\title{
Somatosensory System Deficits in Schizophrenia Revealed by MEG during a Median-Nerve Oddball Task
}

\author{
Ming-Xiong Huang $\cdot$ Roland R. Lee $\cdot$ Kathleen M. Gaa $\cdot$ Tao Song $\cdot$ \\ Deborah L. Harrington • Cathy Loh - Rebecca J. Theilmann • \\ J. Christopher Edgar · Gregory A. Miller · Jose M. Canive · Eric Granholm
}

Received: 9 June 2009/ Accepted: 12 November 2009/Published online: 27 November 2009

(C) The Author(s) 2009. This article is published with open access at Springerlink.com

\begin{abstract}
Although impairments related to somatosensory perception are common in schizophrenia, they have rarely been examined in functional imaging studies. In the present study, magnetoencephalography (MEG) was used to identify neural networks that support attention to somatosensory stimuli in healthy adults and abnormalities in these networks in patient with schizophrenia. A median-nerve oddball task was used to probe attention to somatosensory stimuli, and an advanced, high-resolution MEG source-imaging method was applied to assess activity throughout the brain. In nineteen healthy subjects, attention-related activation was seen in a sensorimotor network involving primary somatosensory (S1), secondary somatosensory (S2), primary motor (M1), pre-motor (PMA), and paracentral lobule (PCL) areas. A
\end{abstract}

M.-X. Huang - R. R. Lee · D. L. Harrington - C. Loh ·

E. Granholm

Research, Radiology, and Psychiatry Services,

VA San Diego Healthcare System,

San Diego, CA, USA

M.-X. Huang $(\bowtie) \cdot$ R. R. Lee · K. M. Gaa · T. Song •

D. L. Harrington - R. J. Theilmann

Radiology Imaging Laboratory,

Department of Radiology, University of California,

San Diego, 3510 Dunhill Street,

San Diego, CA 92121, USA

e-mail: mxhuang@ucsd.edu

C. Loh · E. Granholm

Department of Psychiatry, University of California, San Diego,

San Diego, CA, USA

J. C. Edgar

Department of Radiology, The Children's Hospital

of Philadelphia, Philadelphia, PA, USA frontal-parietal-temporal "attention network", containing dorsal- and ventral-lateral prefrontal cortex (DLPFC and VLPFC), orbitofrontal cortex (OFC), anterior cingulate cortex (ACC), superior parietal lobule (SPL), inferior parietal lobule (IPL)/supramarginal gyrus (SMG), and temporal lobe areas, was also activated. Seventeen individuals with schizophrenia showed early attention-related hyperactivations in S1 and M1 but hypo-activation in S1, S2, M1, and PMA at later latency in the sensorimotor network. Within this attention network, hypoactivation was found in SPL, DLPFC, orbitofrontal cortex, and the dorsal aspect of ACC. Hyperactivation was seen in SMG/IPL, frontal pole, and the ventral aspect of ACC in patients. These findings link attention-related somatosensory deficits to dysfunction in 
both sensorimotor and frontal-parietal-temporal networks in schizophrenia.

Keywords MEG · Somatosensory · Attention · Schizophrenia · Oddball

$\begin{array}{ll}\text { Abbreviations } \\ \text { ACC } & \text { Anterior cingulate cortex } \\ \text { AG } & \text { Angular gyrus } \\ \text { BA } & \text { Brodmann area } \\ \text { BEM } & \text { Boundary element method } \\ \text { DLPFC } & \text { Dorsal-lateral prefrontal cortex } \\ \text { ERF } & \text { Event-related field } \\ \text { ERP } & \text { Event-related potential } \\ \text { FP } & \text { Frontal pole } \\ \text { FWER } & \text { Family-wise error rate } \\ \text { IPL } & \text { Inferior parietal lobule } \\ \text { LDAEP } & \text { Loudness dependence of } \\ & \text { auditory evoked potentials } \\ \text { M1 } & \text { Primary motor } \\ \text { MFG } & \text { Middle frontal gyrus } \\ \text { MMF } & \text { Magnetic mismatch field } \\ \text { MMN } & \text { Mismatch negativity } \\ \text { MRI } & \text { Magnetic resonance images } \\ \text { MVT } & \text { Medioventral temporal } \\ \text { OFC } & \text { Orbitofrontal cortex } \\ \text { PCC } & \text { Posterior cingulate cortex } \\ \text { PCL } & \text { Paracentral lobule } \\ \text { PMA } & \text { Pre-motor area } \\ \text { PPC } & \text { Posterior parietal cortex } \\ \text { S1 } & \text { Primary somatosensory } \\ \text { S2 } & \text { Secondary somatosensory } \\ \text { SMA } & \text { Supplementary motor area } \\ \text { SMG } & \text { Supramarginal gyrus } \\ \text { SPL } & \text { Superior parietal lobule } \\ \text { SSP } & \text { Signal space separation } \\ \text { STS } & \text { Superior temporal sulcus } \\ \text { TP } & \text { Temporal pole } \\ \text { VESTAL } & \text { Vector-based spatial-temporal analysis using } \\ \text { VLPFC } & \text { Ventral-lateral prefrontal cortex } \\ & \end{array}$

\section{Introduction}

Individuals with schizophrenia commonly exhibit a variety of symptoms related to the somatosensory system. About $30-50 \%$ of first-episode patients experience somatic delusions and tactile hallucinations (Johnstone et al. 1986; Johnstone et al. 1991). Impairments related to somatosensory perception are also common, including fine motor touch, temperature, pain (nociception), movement, tension, and vibration (Ritzler and Rosenbaum 1974; Dworkin 1994; Kolb and Whishaw 1996). Deficits have also been found in individuals with schizophrenia, their relatives, and individuals with schizotypal personality disorder on tests of somatosensory function, including two-point discrimination and graphesthesia (Martin et al. 1995; Lenzenweger 2000; Chang and Lenzenweger 2001; Lenzenweger et al. 2002; Chang and Lenzenweger 2004; Chang and Lenzenweger 2005). Cognitive processes associated with somatosensory perception have also been examined (see review in (Chang and Lenzenweger 2004)). For example, it was found that somatosensory stimulation in a group of individuals with schizophrenia was associated with decreased activity in brain regions participating in an attentional network (Boning et al. 1989).

Somatosensory deficits may have a profound impact on quality of life, including the performance of jobs that require the use of tools, such as a car mechanic, carpenter, seamstress, dishwasher, or butcher; as well as more academic jobs, such as musician, painter, and sculptor. These jobs require accurate processing of somatosensory feedback to guide hand movements. Little is known, however, about the neural substrates supporting somatosensory processing impairments in schizophrenia. Although functional imaging research in schizophrenia has played an important role in understanding neurobiological factors in cognitive dysfunction, the somatosensory system has rarely been examined. Norra and colleagues (Norra et al. 2004) reported prolonged high-frequency oscillations $(\sim 600 \mathrm{~Hz})$ and higher amplitude in the low-frequency range of the N20 component in patients with schizophrenia than controls. A few early studies using EEG to examine basic somatosensory responses provided evidence of abnormal somatosensory activity in patients with schizophrenia. As examples, Shagass and colleagues (Shagass et al. 1978) observed an abnormal topography of later somatosensory responses in patients with schizophrenia (Shagass et al. 1978), and they also used somatosensory, visual, and auditory evoked potentials to discriminate between psychiatric groups (Shagass et al. 1985). With limited spatial information from these previous neuroimaging studies, however, it is difficult to develop a model of somatosensory dysfunction in schizophrenia that can be used to guide the development of treatments to reduce somatosensoryrelated cognitive deficits and to improve quality of life for these individuals.

Cognitive deficits in schizophrenia are most apparent in laboratory or real-life situations that place a burden on attentional resources. For example, cognitive deficits are accentuated when information must be processed rapidly, especially in the presence of distracting events, or when an activity involves high processing loads and multi-tasking 
(Braff 1999). The neural mechanisms related to these impairments have been assessed primarily in the auditory system and to a lesser extent in the visual system by studying neuronal responses, such as the auditory P50 and N100 components of the event-related brain potential (ERP), the auditory M50 and M100 event-related field (ERF), mismatch negativity (MMN), and the P300 ERP. Loudness dependence of auditory evoked potentials (LDAEP) has also been studied in schizophrenia as an indicator of brain serotonin system's activity. It was found that patients with schizophrenia showed weaker LDAEP (indicating high serotonergic activity) than healthy controls (Juckel et al. 2003, 2004, 2008; Gudlowski et al. 2009).

Examining early activity within the auditory system, many studies have observed encoding abnormalities in individuals with schizophrenia (Clementz and Blumenfeld 2001; Johannesen et al. 2005; Brockhaus-Dumke et al. 2008; Edgar et al. 2008; Turetsky et al. 2008). An inability to enhance or facilitate responses to deviant, novel, or salient stimuli has also been observed. The mismatch response, first described by Näätänen and colleagues (Naatanen et al. 1987; Naatanen and Alho 1997; Naatanen 2001, 2003), provides a measure of the pre-attentive detection of a difference in the attributes of an infrequently presented "deviant" stimulus compared to the properties represented in the memory trace of frequently presented "standard" stimuli. The MMN and magnetic mismatch field (MMF) response can be obtained using visual, haptic, and auditory stimuli. A MMN is usually seen in the difference ERP wave between the standard and deviant conditions of an oddball paradigm, peaking at 120-250 ms post-stimulus latency, depending on the stimulus modality and the presentation parameters (Giese-Davis et al. 1993; Naatanen and Alho 1995; Naatanen 1995; Alho 1995; Lang et al. 1995; Fernandes et al. 1999; Valkonen-Korhonen et al. 2003). Studies have reported attenuated MMN (hypoactivation) in previously medicated or chronic schizophrenia patients (Shelley et al. 1991; Javitt et al. 1993; Catts et al. 1995; Javitt et al. 1995; Matsuoka et al. 1996; Oades et al. 1997; Alain et al. 1998; Umbricht et al. 1998; Kasai et al. 1999; Kreitschmann-Andermahr et al. 1999; Kreitschmann-Andermahr et al. 2001; Pekkonen et al. 2002; Park et al. 2002; Shinozaki et al. 2002; Light and Braff 2005). MMN hypoactivity was also reported in unmedicated patients (Catts et al. 1995) and has typically been localized to the superior temporal lobe (Thonnessen et al. 2008).

Auditory, and to less extent visual, oddball paradigms have also revealed a reduction in individuals with schizophrenia of the P300 component, a response related to attention to important environmental stimuli (Pritchard 1986; Pfefferbaum et al. 1989; Ford et al. 1992; Polich and Kok 1995; Jeon and Polich 2001, 2003). P300 hypoactivation is a reliable, widely used electrophysiological measure of cognitive disturbance in schizophrenia (Friedman 1991; Higashima et al. 1998; Mathalon et al. 2000; Bramon et al. 2004). For example, Wang et al. (2003) reported a frontal-parietal-temporal network that showed strong activation in healthy controls but this network was only "faintly" activated in individuals with schizophrenia. A reduced P300 is also accompanied by poor performance on tests of auditory and visual attention. This P300 deficit has been attributed to a variety of mechanisms including: (1) a failure in early auditory processing, (2) a deficit in sensory memory trace formation, (3) abnormalities in deviance detection processes, or (4) problems in attention (Shean and Faia 1975; Ikebuchi et al. 1996; Carter et al. 1997; Kasai et al. 1999; ValkonenKorhonen et al. 2003).

Reduced MMN/MMF and P300 in schizophrenia are thought to be related to disconnections in frontal-temporal and frontal-parietal neuronal networks that support attention and working memory. The implications of these cognitive deficits for real-world function, quality of life, and clinical management are beginning to receive considerable attention as a matter of both scientific priority and public policy (Green et al. 2004). A key issue not addressed is whether impairments related to the burden on attentional resources are limited to the auditory system or are observed in multiple sensory systems.

The main goals of this study were to identify networks that support somatosensory attention in healthy adults and to determine whether these networks are dysfunctional in schizophrenia. If so, it was predicted that patients with schizophrenia would show abnormal activation at both early and later latencies in the somatosensory system, as has been found with P50/N100, M50/M100, MMN, and P300 in the auditory system. Moreover, if attention-related somatosensory deficits in schizophrenia are partially due to abnormal function of a supramodal attention and workingmemory network, activation of the frontal-parietal-temporal network should be diminished in patients relative to healthy controls. The high temporal ( $<1$ millisecond) and spatial (several millimeters) resolution of MEG make it a powerful tool for studying neural mechanisms of somatosensory processing and thus for identifying abnormalities in attention-related somatosensory processing.

\section{Materials and Methods}

Schizophrenia Patients and Healthy Control Participants

Seventeen patients with chronic schizophrenia (age $=$ $42.5 \pm 11.8$ years; 11 males; 15 right-handed) and 19 
age-matched healthy controls (age $=38.8 \pm 11.5$ years; 13 males; 16 righted-handed) participated in this study. Groups did not differ in age $(t=0.96, P=0.34$, df $=34)$. Healthy control subjects met the following criteria: (1) no history of psychiatric dysfunction and no alcohol abuse or other substance abuse in the three months prior to entry into the study as determined by the DSM-IV SCID-NP; (2) no family history of a psychotic disorder in first-degree relatives as assessed by FH-RDC diagnostic interview; (3) no history of head injury with loss of consciousness for more than five minutes; (4) age 18-65; and (5) capacity to sign the Informed Consent. Patients with schizophrenia met the following selection criteria: (1) diagnosis of schizophrenia determined by the SCID-Patient Edition; (2) continuous treatment with the same antipsychotic medications for at least three months; (3) no history of alcohol abuse or other substance abuse in the three months prior to entry into the study; (4) no history of head injury with loss of consciousness for more than five minutes; (5) no mood stabilizing agents; (6) no psychiatric hospitalization in the last three months; (7) age 18-65; and (8) signed Informed Consent. The mean ( \pm SD) duration of illness was $21.9 \pm 9.1$ years. Patients were receiving stable therapeutic doses of antipsychotics (1 on haloperidol, 2 on clozapine, 2 on olanzapine, 2 on aripiprazole, 2 on risperidone, 2 on quetiapine, 2 on fluoxentine, 1 on fluphenazine, 2 on both ziprasidone and fluoxentine, 1 on ziprasidone, quetiapine, and fluoxentine). Patients were assessed with the PANSS, and the symptom scores (mean \pm SD) were $14.2 \pm 4.5$ for PANSS Positive Scale, $13.8 \pm 5.1$ for PANSS Negative Scale, $30.4 \pm 7.1$ for PANSS general scale, and $58.3 \pm 14.5$ for PANSS total score.

\section{Median-Nerve Oddball Task}

Subjects performed an oddball task developed in our lab (Huang et al. 2005). During the task, painless electrical stimuli were presented to right or left median nerves via electrode pairs taped to each wrist with electrode separation of $2 \mathrm{~cm}$. The stimuli were square-wave pulses (0.25 ms duration) generated by a bipolar GRASS ${ }^{\mathrm{TM}}$ stimulator. The intensity of the stimulation was adjusted until robust thumb twitches were obtained. A trigger from the stimulator, simultaneous with the stimulus, was sent to the MEG acquisition system for signal averaging.

Stimuli were presented in series of 4 blocks. Blocks 1 and 3 were the same, as were Blocks 2 and 4 . A diagram of the organization of Blocks 1 and 2 is shown in Fig. 1. In Blocks 1 and $3,15 \%$ of the stimuli were delivered to the right wrist and $85 \%$ to the left wrist. Subjects were instructed to attend to and count silently the rare stimuli to the right wrist while ignoring the frequent stimuli to the left wrist. In Blocks 2 and 4, 85\% of the stimuli were delivered to the right wrist and $15 \%$ to the left wrist. Subjects were instructed to attend to and count the rare stimuli on the left wrist while ignoring the frequent stimuli to the right wrist. The inter-stimulus interval was 1000 ms. After each block, the number of rare stimuli counted by the subject was recorded. After discarding trials with artifacts (e.g., eye blinks, large eye movements), MEG trials from Blocks 1 and 3 were concatenated, as were the trials from Blocks 2 and 4. For each wrist, $\sim 150$ trials of rare MEG responses and $\sim 850$ trials of frequent responses were averaged to create two averaged files - one for rare and one for frequent responses. Then for each side, the rare and frequent MEG conditions were compared as indicated by arrows in Fig. 1. The order of Blocks 1 and 2 (and accordingly Blocks 3 and 4) was randomized across subjects. This paradigm contrasts with previous somatosensory oddball studies in which the rare and frequent stimuli were presented as: (1) different modalities (e.g., somatosensory and auditory, or somatosensory and visual), (2) the same somatosensory modality but with different stimulation sites of the body, or (3) the same stimulation site but with different stimulation intensities (Desmedt and Tomberg 1989; Hari et al. 1990; Yamaguchi and Knight 1991; Garcia-Larrea et al. 1995; Kekoni et al. 1996; Mauguiere et al. 1997b; Mima et al. 1998; Fujiwara et al. 2002). Here, attention to rare stimuli was not confounded by different stimulus modalities or other stimulation parameters (e.g., site, intensity). Rather, attention-related changes were directly assessed by subtracting the frequent responses from the rare responses on each side of the body (Fig. 1). Another advantage of this design is that the task is easy to perform, and the accuracy of counting the rare stimuli in patients with schizophrenia was similar to that of the healthy controls (see "Results").
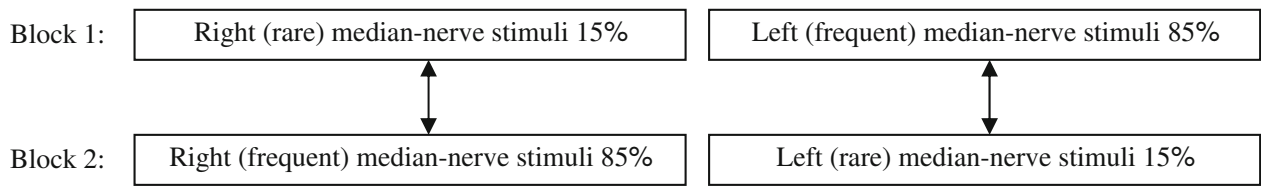

Fig. 1 Median-nerve oddball paradigm. Block 1: 15\% of the stimuli were delivered to the right wrist and $85 \%$ to the left wrist. Subjects were instructed to count silently the rare stimuli to the right wrist. Block 2: the rare and frequent stimuli were reversed, and subjects were instructed to silently count the rare stimuli to the left wrist. For each side, oddball MEG signals were obtained by subtracting the frequent responses from the rare responses across different blocks as indicated by the arrows. Block 3 was identical to Block 1, and Block 4 was identical to Block 2 
MEG and Anatomical MRI Data Acquisition and Co-registration

Brain responses were recorded by a VectorView ${ }^{\mathrm{TM}}$ wholecortex MEG system from Elekta-Neuromag (Helsinki, Finland) with 306 channels (204 planar gradiometers and 102 magnetometers). This system is located in an enhanced, magnetically shielded room (IMEDCO-AG, Switzerland) containing three layers of mu-metal, three layers of aluminum coated with gold at the junctions, and one layer of active compensation (Cohen et al. 2002). Two pairs of EOG electrodes were used to detect eye blinks and eye movements. Trials coincident with eye blinks and large eye movements were excluded. During the 4-block recording session, precautions were taken to ensure head stability: Foam wedges were inserted between the subject's head and the inside of the unit, and a Velcro strap was placed under the subject's chin and anchored in superior and posterior axes. For each epoch, an interval $500 \mathrm{~ms}$ post-stimulus was selected for the averaged response from the raw MEG data, and a $300 \mathrm{~ms}$ pre-stimulus interval was used for noise estimation and baseline removal. The A/D sampling rate was $1000 \mathrm{~Hz}$, and the data were run through a high-pass filter with $0.1 \mathrm{~Hz}$ cut-off, a low-pass filter with $330 \mathrm{~Hz}$ cut-off, and a notch filter $(58-62 \mathrm{~Hz})$ to remove $60 \mathrm{~Hz}$ power-line noise.

To enable MEG source modeling, 3D volumetric magnetic resonance images (MRI) were acquired with voxels of $0.94 \times 0.94 \times 1.2 \mathrm{~mm}^{3}$ on a GE 1.5T Excite HDx MRI scanner (ver. 14 software release). The T1-weighted anatomical dataset was acquired in the sagittal plane with a 3D-IRSPGR pulse sequence for an approximate total imaging time of 8 minutes $(\mathrm{TR}=6.5 \mathrm{~ms}, \mathrm{TE}=2.8 \mathrm{~ms}$, $\mathrm{TI}=600 \mathrm{~ms}$, flip angle $=12^{\circ}, \mathrm{FOV}=24 \mathrm{~cm}$, whole brain coverage, slice thickness $=1.2 \mathrm{~mm}, 170$ slices).

To co-register the MEG and MRI data, four small coils were attached to each subject's head during the preparation phase of the MEG session. A Polhemus system was used to digitize the location of the coils and three anatomical landmarks (nasion, left and right preauricular). The coils were activated briefly by sinusoidal current at the beginning and the end of the MEG session to specify the position and orientation of the MEG sensors relative to the head. By identifying the same anatomical landmarks on the subject's MR images, using Elekta-Neuromag software, a rigid-body transformation matrix involving rotation and translation between the MEG and the MRI coordinate systems was generated to coregister the functional MEG data to the anatomical structure. To increase the reliability of the MEG-MRI coregistration, approximately 80 additional points on the scalp were digitized with the Polhemus system. Based on previous experience with this protocol and in line with the review of Miller, Elbert, Sutton, and Heller
(Miller et al. 2007), the MEG-MRI co-registration error in the present study was expected to be less than $3 \mathrm{~mm}$.

Signal Space Separation and Correction of Head Motion across Blocks during MEG

Although foam wedges and Velcro straps eliminate large head movement during MEG recordings, small head motion is still possible, typically between trial blocks. In the present study, Signal Space Separation (SSS) was used to ensure alignment of the head position across different blocks. SSS (Turetsky et al. 2004) and its spatio-temporal variant (Taulu and Simola 2006), part of the Elekta-Neuromag MEG system, are new, powerful methods for removing external interference and sensor artifacts. SSS also enables an effective head-movement correction method comprised of disturbance removal followed by a virtual signal calculation for the desired reference position of the head (Cheour et al. 2004; Taulu et al. 2004a; Turetsky et al. 2004b).

MEG Forward Modeling with Realistically-shaped Head Model

To localize neuronal sources and obtain their time course, one needs to solve the MEG forward and inverse problems. In MEG forward models, the magnetic field distribution at sensors is calculated from a given source configuration and the conductivity distribution of different compartments of the head. Typical head models assume that the head contains several homogeneous layers (e.g. scalp, skull, and brain). The present study used a realistically shaped Boundary Element Method (BEM) MEG head model (Hamalainen and Sarvas 1989; Ferguson et al. 1994; Schlitt et al. 1995; Mosher et al. 1999; Gencer and Tanzer 1999; Cuffin et al. 2001). With BEM, the conductivity within each compartment of the head is assumed to be constant, and surfaces of the compartments (e.g., scalp, outer-skull, and inner-skull surfaces extracted from the 3D volumetric MRI) are tessellated with $\sim 5000$ small triangles per surface (boundary elements); forward magnetic fields are calculated using this realistically shaped head model (Mosher et al. 1999).

\section{MEG Source Imaging using VESTAL}

Brain activations were obtained with Vector-based SpatialTemporal Analysis using L1-minimum-norm (VESTAL), an advanced, high-resolution MEG source imaging method recently developed (Huang et al. 2006) in MATLAB (Mathworks Inc, MA) with the data input routine from MNE software (http://www.nmr.mgh.harvard.edu/meg/). 
In the VESTAL approach, temporal information in the data is used to enhance the stability of the reconstructed vectorbased L1-minimum norm solution. Because this approach makes no additional assumptions about the temporal dynamics of the sources, it can resolve sources that are $100 \%$ correlated. VESTAL also effectively obtains unbiased source strength and dipole orientation, without iteration or choosing a predetermined dipole orientation. VESTAL has been tested extensively in computer simulations and data from human MEG responses, and results show that VESTAL provides high spatial stability and continuous temporal dynamics, without compromising high spatial or temporal resolution (Huang et al. 2006).

In the VESTAL approach, the T1-weighted images were used for gray-white matter segmentation with Freesurfer (Dale et al. 1999; Fischl et al. 2004) to obtain the highresolution cortical surface. Then, the cortical surface was decimated into a grid of about 7000 nodes. This cortical grid, plus about 1000 nodes for cerebellum, was used as the source grid for VESTAL. With SSS, small head position differences across the four blocks in the median-nerve oddball task were eliminated, and a difference waveform for each sensor was obtained by subtracting the trialaveraged MEG responses evoked by (non-target) frequent stimuli from those evoked by (target) rare stimuli. This difference waveform is directly related to attention and was the response analyzed by VESTAL. The interval of the VESTAL analysis was from $300 \mathrm{~ms}$ pre-stimulus to $500 \mathrm{~ms}$ post-stimulus, with the $-10 \mathrm{~ms}$ to $+10 \mathrm{~ms}$ interval removed due to strong stimulus artifacts from the electric stimulation. The result of the VESTAL analysis was a $2 \mathrm{D}$ source time-course matrix with rows being the nodes in the source space and columns being the time points (pre- and post-stimulus interval).

\section{Group Statistical Analysis of the VESTAL Solutions}

Using the VESTAL solutions from each subject, two groupwise statistical analyses were performed. The first was a within-group analysis (healthy control or schizophrenia group) that assessed statistical significance of post-stimulus activity during certain latencies (intervals) relative to the pre-stimulus baseline. The second was a between-group analysis assessing differences between healthy control and schizophrenia groups in the post-stimulus intervals.

A non-parametric cluster-based permutation test was used to address the multiple-comparisons problem and to control family-wise error across subjects in time and space. This approach has been applied to MEG and EEG data (Blair and Karniski 1993; Karniski et al. 1994; Galan et al. 1997; Kaiser et al. 2000; Achim 2001; Lutzenberger et al. 2002; Nichols and Holmes 2002; Barnes and Hillebrand 2003; Kaiser et al. 2003; Maris 2004; Chau et al. 2004;
Kaiser and Lutzenberger 2005; Pantazis et al. 2005; Kaiser et al. 2006; Maris and Oostenveld 2007). The cluster-permutation approach was used to control family-wise error rate (FWER) and assess statistical significance in space, time, and across groups of subjects (Maris and Oostenveld 2007; Maris et al. 2007). The software for this statistical tool is available at: http://www.ru.nl/fcdonders/Fieldtrip.

Specifically, to perform within-group comparisons in the healthy control subjects, VESTAL source time-courses (source amplitudes changing with time) in the post-stimulus interval were compared with the pre-stimulus baseline interval using a one-sample $t$-test. To assess group differences between the healthy controls and schizophrenia patients, a two-sample $t$-test was used to examine the posstimulus VESTAL source activities.

The Fieldtrip cluster-based analysis identified $t$-value clusters in space (source grid) and time simultaneously with random permutation-based sampling. The minimum numbers of neighboring cluster-bins in time and dipole nodes are 2 and 4, respectively. Three thousand draws were performed in the permutation test for both the within-group (pre- and post-stimulus difference) and between-group analysis. Before the group analyses, the VESTAL maps from individual subjects were registered to an averaged brain surface after applying a $10 \mathrm{~mm}$ spatial smoothing step using Freesurfer (http://surfer.nmr.mgh.harvard.edu), to reduce effects of cross-subject variations in local anatomy and enhance sensitivity. An advantage of the VESTAL approach is its high degree of sparseness in the functional activity images, with the majority $(>85 \%)$ of grid nodes showing essentially zero $(<0.001 \mathrm{nAm})$ activity, thereby reducing the problem of multiple comparisons in the spatial domain.

The FWER was controlled with the spatio-temporal cluster of $t$-values with a Monte Carlo $P$-value less than 0.01 and 0.001 for assessing the post-stimulus versus prestimulus difference within the healthy control subjects. For the assessment of group differences between healthy control subjects and schizophrenia patients, the thresholds of the FWER-corrected $P$-value were set at 0.05 and 0.01 . Three thousand draws were performed in the permutation test for both the within group (pre- and post-stimulus difference) and between-group analyses.

To use Fieldtrip's permutation random re-sampling procedures to control FWER, it was necessary that the preand post-intervals had the same number of time points. With sampling frequency of $1000 \mathrm{~Hz}$, the pre-stimulus interval contained 290 time points and the post-stimulus interval had 490 time points (to avoid the stimulus artifact at $0 \mathrm{~ms}$, the interval of $\pm 10 \mathrm{~ms}$ around the stimulus was excluded). The shorter pre-stimulus interval allowed the brain responses to return to baseline. In the present study, the existing pre-stimulus baseline of MEG sensor 
waveform was randomly re-sampled by repetition to form a new pre-stimulus interval with 490 time-points. For every subject, there was no significant difference between the newly formed pre-stimulus interval with 490 time points and the original 290 time point interval for each MEG channel.

\section{Results}

MEG Sensor Waveforms for Attention to Median-nerve Oddball Stimuli

Accuracy in identifying the rare stimuli in healthy controls was $97.5 \pm 1.8 \%$ (mean $\pm \mathrm{SD}$ ). Figure $2 \mathrm{a}$, e show the trial-averaged MEG sensor waveforms evoked by the frequent stimuli delivered to one representative healthy control subject's right median-nerve. The MEG waveforms from 204 gradiometer channels and 102 magnetometer channels are superimposed in Fig. 2a, e, respectively. The spike at $0 \mathrm{~ms}$ is the stimulus artifact. The first and second sharp peaks (indicated by arrows in Fig. 2a) at $20 \mathrm{~ms}$ and $30 \mathrm{~ms}$ with different polarities are the $\mathrm{N} 20 \mathrm{~m}$ and $\mathrm{P} 30 \mathrm{~m}$ cortical components (the magnetic counterparts of the N20 and P30 in the ERP), which are generated mainly from primary somatosensory cortex (Hari et al. 1993; Forss et al. 1994; Kawamura et al. 1996; Mauguiere et al. 1997a; Mauguiere et al. 1997b; Jousmaki and Forss 1998; Forss and Jousmaki 1998; Hari and Forss 1999; Huang et al. 2000; Huang et al. 2004a; Huang et al. 2006) and primary motor cortex (Rosen and Asanuma 1972; Lemon and Porter 1976; Jones et al. 1978; Jones et al. 1979; Lemon and van der Burg 1979; Asanuma et al. 1980; Lemon 1981; Davidoff 1990; Baldissera and Leocani 1995; Kawamura et al. 1996; Spiegel et al. 1999; Huang et al. 2000; Huang et al. 2004b; Huang et al. 2006).

In Fig. 2b, f, MEG responses evoked by rare mediannerve stimuli from the same subject are plotted. Compared to the frequent condition, the signals in the rare condition showed a marked increase in the amplitude of many components. Because a major focus of the present study was the location and temporal dynamics of the neuronal sources that show attention-related changes, the waveforms of the difference waveforms (i.e., responses evoked by rare stimuli minus those evoked by frequent stimuli) are plotted in Fig. 2c, g. These graphs show that the sharp N20m and $\mathrm{P} 30 \mathrm{~m}$ are not present in the difference-waveform plot, a strong indication that these components were unaltered by attention.

The earliest attention-related response starts at $\sim 40 \mathrm{~ms}$ and peaks at $\sim 75$ and $\sim 150 \mathrm{~ms}$, etc. as shown in Fig. $2 \mathrm{c}$, g. The rare minus frequent responses for the entire $500 \mathrm{~ms}$ interval are shown in Figs. 2d, h for gradiometers and magnetometers, respectively. Later peaks can be seen at $\sim 220$, 300, and $\sim 450 \mathrm{~ms}$.

VESTAL Result for Rare-minus-frequent Different Responses in Left Hemisphere due to Contralateral Stimuli in Healthy Controls

The rare-minus-frequent difference waveforms from control subjects were analyzed using VESTAL. Figure 3a displays snapshots of the group-averaged MEG activity maps in the left hemisphere that were associated with the difference response from the contralateral right mediannerve oddball stimuli. The inflated brain surface from an averaged brain obtained from Freesurfer software (Dale et al. 1999; Fischl et al. 2004) was used to display the neuronal activation in lateral, ventral, and medial views, with the medial view oriented upside-down to preserve the anterior-posterior orientation in all three views. The cerebellum is not displayed, as significant activation was not detected in this brain region.

The statistical threshold was set at $P=0.01$ (adjusted for FWER) to test within-group statistical significance at different post-stimulus latencies against the pre-stimulus baseline. The latencies of the snapshots at $\sim 40, \sim 80$, $\sim 140, \sim 220, \sim 300$, and $\sim 450 \mathrm{~ms}$ were chosen at the peak latencies of the sensor waveforms and to highlight the attention-related early somatosensory responses and later latencies that are consistent with the MMN and P300 components.

The VESTAL result based on the difference waveform (rare-minus-frequent) did not show statistical significance for any latency less than $35 \mathrm{~ms}$, compared with the prestimulus baseline data. Since the N20m and P30m did not change when evoked by rare and frequent median-nerve stimuli, these two components did not contribute to the attention-related difference activation. The earliest attention-related neuronal activation in the rare-minus-frequent difference response was observed at $\sim 40 \mathrm{~ms}$. At $\sim 40 \mathrm{~ms}$, primary somatosensory $\mathrm{S} 1$ (BA $3 \mathrm{~b}, 1,2)$, primary motor M1 (BA 4), and dorsal pre-motor PMA (BA 6) areas showed strong attention-related activation. Weaker activation was also seen in the dorsal aspect of posterior parietal cortex (PPC)/superior parietal lobule (SPL) in BA 7. (Through this subsection, strong activation is defined as $P<0.001$, and weaker activation is defined as $0.001<P<0.01$.)

Figure 3 shows that left-hemisphere activation at $\sim 80 \mathrm{~ms}$ extended into the secondary somatosensory area S2 (BA 43 and anterior aspect of BA 40; white arrow), dorsal and ventral PMA, supramarginal gyrus SMG/inferior parietal lobule IPL (superior and posterior aspect of BA 40; dark blue arrow), PPC/SPL, and ventral lateral pre-frontal cortex (VLPFC; BA 45 and BA 47; cyan arrow). In addition, the 

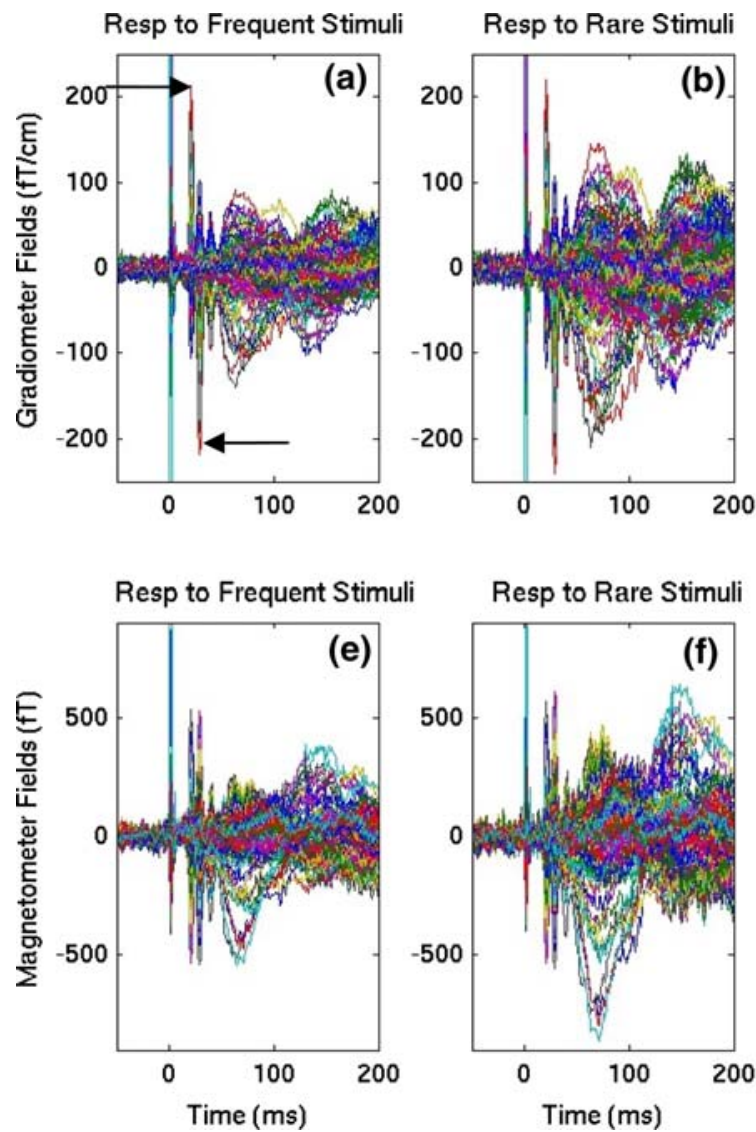

Fig. 2 MEG sensor waveforms from 204 gradiometer channels (102 pairs of co-located orthogonal pairs; top row) and 102 magnetometer channels (bottom row) in a representative healthy control participant evoked by right median-nerve oddball stimuli averaged over "frequent" and "rare" trials. a Gradiometer waveforms for the first $200 \mathrm{~ms}$ interval evoked by frequent stimuli. The two arrows indicate the sharp N20m and P30m components. b Gradiometer waveforms for

ventral and medial views of the left hemisphere showed activation in the medial aspect of the orbitofrontal cortex (mOFC, BA 11; magenta arrow), medioventral temporal lobe MVT (BA 28, 35, 36), temporal pole area TP (BA 38), and the paracentral lobule PCL (BA 5).

At $\sim 140 \mathrm{~ms}$, the typical latency for auditory MMN, the most interesting findings were activation in dorsal lateral prefrontal cortex (DLPFC; BA 46, 9; red arrow) and PPC/ SPL (yellow arrow) of the left hemisphere. In addition, activation in S1, S2, M1, dPMA, vPMA, SMG became stronger at $\sim 140 \mathrm{~ms}$ than at $\sim 80 \mathrm{~ms}$. The ventral and medial views showed that the $\mathrm{mOFC}$ and temporal pole areas remained active. The supplementary motor area (SMA) also showed weak activation at this latency. At $\sim 220 \mathrm{~ms}$, attention-related activation was still seen in S1, S2, M1, dPMA, PPC/SPL, DLPFC, mOFC, and TP areas. The posterior aspect of the PPC/SPL also showed strong activation at this latency. In addition, the lateral view of the left hemisphere began to show activation in the lateral temporal lobe

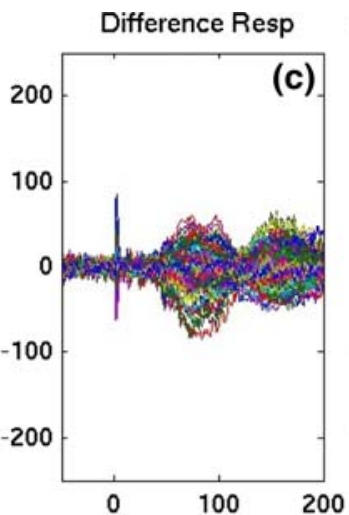

Difference Resp, whole interval
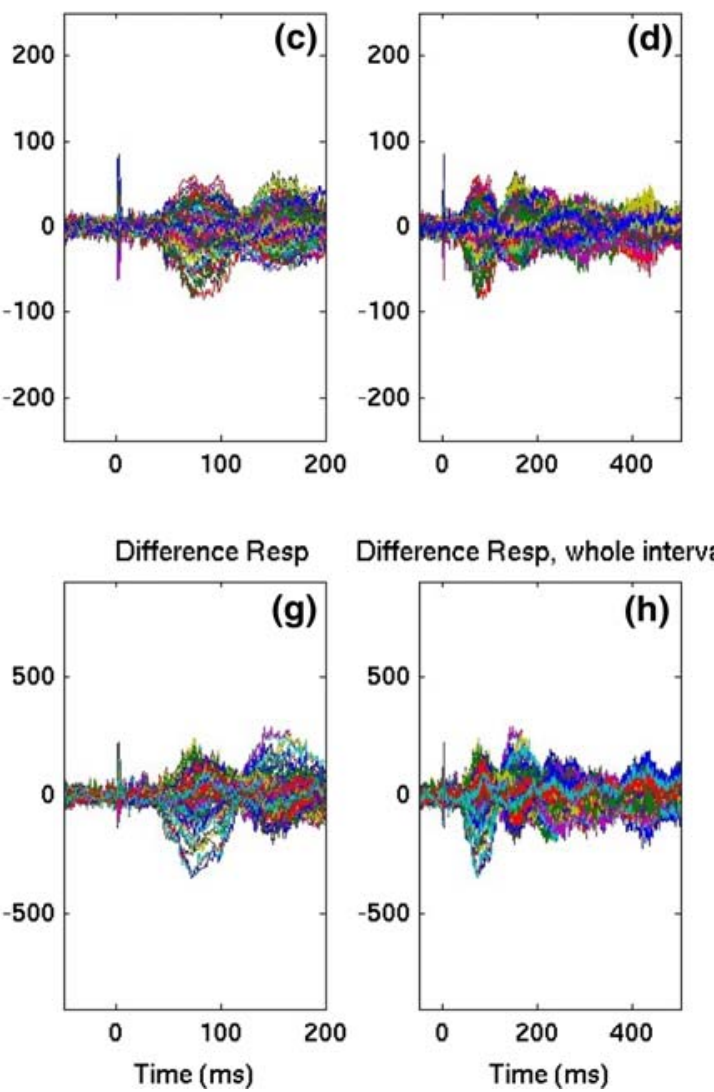

rare stimuli. Note the marked increase in averaged signal amplitude. $\mathbf{c}$ Gradiometer waveforms of rare minus frequent oddball responses. d Same as c, but for the whole $500 \mathrm{~ms}$ interval. The bottom row displays magnetometer waveforms for the frequent (e), rare (f), rare minus frequent responses for the first $200 \mathrm{~ms}$ (g), and for the whole $500 \mathrm{~ms}$ interval $(\mathbf{h})$, respectively

in superior temporal sulcus (STS, BA 21, 22). At $\sim 300 \mathrm{ms,}$ the typical latency for P300, activation was seen in S1, S2, vPMA, mOFC, and PCL. The temporal pole and STS (green arrow) areas showed strong activation. At this latency, the left insula also showed strong activation, although the onset of insula cortex activation started earlier, at $\sim 140 \mathrm{~ms}$. In the snapshot of the latest examined activity, at $\sim 450 \mathrm{~ms}$, the most prominent activation was seen in the $\mathrm{mOFC}$ and anterior cingulate cortex (ACC, BA 32). S1, S2, M1, vPMA, STS, and TP areas also remained active, and insula cortex showed activation at this latency as well.

The middle columns in Table 1 summarize attentionrelated activation in the left hemisphere in response to oddball stimuli delivered to the right (contralateral) mediannerve in healthy controls. The sources are grouped into four categories in the left column. Group 1 contains sources in somatosensory and motor systems: S1, S2, M1, dPMA, vPMA, PCL, SMA and insula. Group 2 contains sources in the posterior parietal lobe: SMG/IPL, dPPC/SPL, and 
Fig. 3 Attention-related brain activations (rare minus frequent responses) in the control group derived from the VESTAL method. a Left-hemisphere activation, evoked by contralateral median-nerve stimulation of the right arm. b Left-hemisphere activation, evoked by ipsilateral stimulation of the left arm. c Right-hemisphere activation, evoked by contralateral stimulation of the left arm. d Right-hemisphere activation, evoked by ipsilateral stimulation of the right arm. FWER was controlled at $P=.01$ level

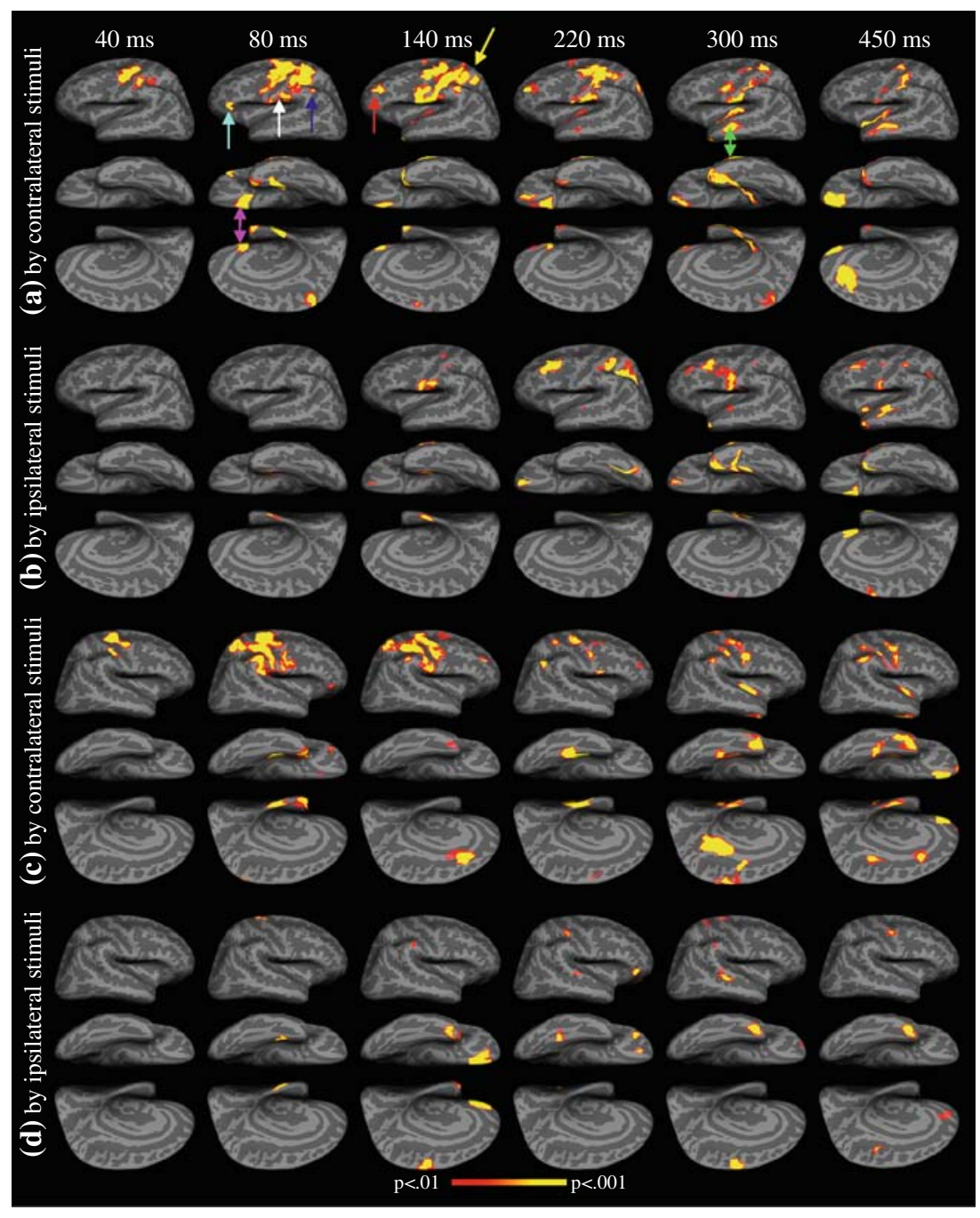

nerve stimulation in control subjects. In general, sources in the right hemisphere and their latencies were very similar to those in the left hemisphere for contralateral stimuli sources (Fig. 3a). One notable difference was the strong activation in posterior cingulate cortex (PCC) at $\sim 300 \mathrm{~ms}$ in the right hemisphere (medial view of Fig. 3c). The right ACC also showed strong activation at $\sim 130 \mathrm{~ms}$ that was not seen in left ACC at that latency. Another difference is the activation in angular gyrus (AG, BA 39) at $\sim 220 \mathrm{~ms}$. The DLPFC and VLPFC activity in the right hemisphere appears to be weaker than that in the left hemisphere, but their latencies are similar.

Attention-related Activations in Right Hemisphere due to Ipsilateral Stimuli in Healthy Controls

Figure $3 \mathrm{~d}$ and Table 2 (right columns) show activation in the right hemisphere evoked by ipsilateral (right) mediannerve stimulation. Compared with the sources in the left hemisphere also with ipsilateral stimuli (Fig. 3b), the TP, MVT, mOFC, and STS showed very similar activations 
Table 1 Neuronal sources in the left hemisphere evoked by oddball stimuli delivered to the contralateral and ipsilateral median-nerves in healthy controls

\begin{tabular}{|c|c|c|c|c|c|c|c|c|c|c|c|c|}
\hline \multirow[b]{2}{*}{ Sourcellatency (ms) } & \multicolumn{6}{|c|}{ Contralateral stimuli } & \multicolumn{6}{|c|}{ Ipsilateral stimuli } \\
\hline & 40 & 80 & 140 & 220 & 300 & 450 & 40 & 80 & 140 & 220 & 300 & 450 \\
\hline $\mathrm{S} 1(\mathrm{BA} 3 \mathrm{~b}, 1,2)$ & $* * *$ & $* * *$ & $* * *$ & $* * *$ & $* * *$ & $* * *$ & & & ** & *** & $* *$ & $* * *$ \\
\hline S2 (BA43, 40) & & $* * *$ & $* * *$ & $* * *$ & $* * *$ & $* *$ & & & $* * *$ & & $* * *$ & $* * *$ \\
\hline M1 (BA 4) & $* * *$ & $* * *$ & $* * *$ & $* * *$ & $* *$ & $* * *$ & & & ** & & & $* *$ \\
\hline DPMA (BA 6) & $* * *$ & $* * *$ & $* * *$ & $* * *$ & & & & & & & & \\
\hline vPMA (BA 6) & & $* * *$ & $* * *$ & & $* * *$ & $* *$ & & & & & $* *$ & \\
\hline PCL (BA 5) & & $* * *$ & & & $* * *$ & & & & & & & \\
\hline SMA (BA 6) & & & $* *$ & & & & & & & & & $* *$ \\
\hline Insula & & & $* *$ & ** & $* * *$ & $* * *$ & & & & & & $* * *$ \\
\hline SMG/IPL (BA 40) & & $* * *$ & $* * *$ & & & & & & & & & \\
\hline AG (BA 39) & & & & & & & & & & & & \\
\hline PPC/SPL (BA 7) & $* *$ & $* * *$ & $* * *$ & $* * *$ & & & & & & $* * *$ & & $* *$ \\
\hline PCC (BA 31) & & & & & & & & & & & & \\
\hline DLPFC (BA 46, 9) & & & $* * *$ & $* * *$ & & & & & & $* * *$ & $* * *$ & $* * *$ \\
\hline VLPFC (BA 45, 47) & & $* * *$ & & & & & & & & & & \\
\hline mOFC (BA 11) & & $* * *$ & $* * *$ & $* * *$ & $* * *$ & $* * *$ & & & ** & $* * *$ & $* * *$ & $* * *$ \\
\hline dACC (BA 32) & & & & & & $* * *$ & & & & & & \\
\hline TP (BA 38) & & $* * *$ & $* * *$ & $* *$ & $* * *$ & $* * *$ & & & & & $* * *$ & $* * *$ \\
\hline MVT (BA28, 35, 36) & & $* * *$ & & & $* * *$ & & & ** & $* * *$ & & $* * *$ & \\
\hline STS (BA 21) & & & & $* *$ & $* * *$ & $* * *$ & & & & $* *$ & ** & $* * *$ \\
\hline
\end{tabular}

$S 1$ primary somatosensory area, $S 2$ secondary somatosensory area, $M 1$ primary motor area, $A P M A$ and $v P M A$ dorsal and ventral pre-motor area, $P C L$ paracentral lobule, $S M A$ supplemental motor area, $S M G / I P L$ supramarginal gyrus/inferior parietal lobule, $A G$ angular gyrus, $P P C$ posterior parietal cortex, $P C C$ posterior cingulate cortex, $D L P F C$ (VLPFC) dorsal (ventral) prefrontal cortex, $m O F C$ medial orbitofrontal cortex, $d A C C$ dorsal anterior cingulate cortex, $T P$ temporal pole, $M V T$ medial ventral temporal area, STS superior temporal sulcus

** and *** indicate $P<.01$, and $P<.001$, respectively

across both hemispheres. In contrast, the most notable differences between the hemispheres were the lack of significant activation in right S2, DLPFC, and PPC/SPL across all latencies in the entire post-stimulus interval. The right SMA showed strong activation at $\sim 140$ and $\sim 300 \mathrm{~ms}$, whereas the left SMA was not significantly activated by ipsilateral median-nerve stimulation at these latencies (although right SMA showed weaker and later activation around $\sim 450 \mathrm{~ms}$ ).

Abnormal Attention-related Activations in Left

Hemisphere due to Contralateral Stimuli

in Schizophrenia Versus Controls

With the neuronal sources and their temporal dynamics mapped out above for healthy control subjects, the abnormalities in schizophrenia patients when processing attention-related information during the median-nerve oddball task can be examined. The schizophrenia patients performed the task similarly to the healthy control subjects, with an accuracy of $96.1 \pm 2.5 \%$ (mean \pm SD). Figure 4a displays snapshots of the left-hemisphere between-group difference in MEG activity maps for the rare-frequent difference response from contralateral right median-nerve stimulation. The statistical threshold was set at $P=0.05$ to examine group differences (this threshold was not as conservative as the $P=0.01$ used in assessing the post-stimulus activation over pre-stimulus baseline within healthy participants, as between-group variance was expected to be larger than the within-group pre- to post-stimulus variability).

The lateral view of the left hemisphere at $\sim 40 \mathrm{~ms}$ (Fig. 4a) shows that the schizophrenia group exhibited more activation than the control group in $\mathrm{S} 1$ but hypoactivation in M1, dPMA, and PPC/SPL. At $\sim 80 \mathrm{~ms}$, hypoactivation in the schizophrenia group was again found in M1, dPMA, vPMA, VLPFC, PPC/SPL, dorsal aspect of S1, mOFC, MVT, TP, and PCL. In addition, hyperactivation in the schizophrenia group was found in $\mathrm{S} 1$ and the ventral aspect of orbitofrontal cortex (vOFC). At $\sim 140 \mathrm{~ms}$, the typical latency of the MMN, the schizophrenia group showed hypoactivation in DLPFC, S1, S2, M1, dPMA, vPMA, SMA, PPC/SPL, and mOFC. In contrast, the vOFC and SMG/IPL showed hyperactivation in the schizophrenia group. Later, at $\sim 220 \mathrm{~ms}$, whereas hypoactivation in the schizophrenia group was seen in S1, S2, M1, dPMA, PPC/SPL, DLPFC, and $\mathrm{mOFC}$ areas, hyperactivation was found in frontal pole 
Table 2 Neuronal sources in the right hemisphere evoked by oddball stimuli delivered to the contralateral and ipsilateral median-nerves in healthy controls

\begin{tabular}{|c|c|c|c|c|c|c|c|c|c|c|c|c|}
\hline \multirow[b]{2}{*}{ Sourcellatency (ms) } & \multicolumn{6}{|c|}{ Contralateral stimuli } & \multicolumn{6}{|c|}{ Ipsilateral stimuli } \\
\hline & 40 & 80 & 140 & 220 & 300 & 450 & 40 & 80 & 140 & 220 & 300 & 450 \\
\hline $\mathrm{S} 1(\mathrm{BA} 3 \mathrm{~b}, 1,2)$ & $* * *$ & $* * *$ & $* * *$ & $* * *$ & $* * *$ & $* * *$ & & & & $* * *$ & $* *$ & \\
\hline S2 (BA 43, 40) & & $* * *$ & $* * *$ & & & $* *$ & & & & & & \\
\hline M1 (BA 4) & $* * *$ & $* * *$ & $* * *$ & $* * *$ & $* * *$ & $* * *$ & & & & & & $* * *$ \\
\hline dPMA (BA 6) & *** & $* * *$ & $* *$ & & & & & $* * *$ & & & $* *$ & \\
\hline vPMA (BA 6) & & $* * *$ & $* *$ & $* * *$ & $* * *$ & ** & & & & & & \\
\hline PCL (BA 5) & & $* * *$ & $* * *$ & & & & & & & & & \\
\hline SMA (BA 6) & & & & $* *$ & $* * *$ & & & & $* * *$ & & $* * *$ & \\
\hline Insula & & & & & $* * *$ & $* * *$ & & & & & & \\
\hline SMG/IPL (BA 40) & & $* * *$ & $* * *$ & & $* * *$ & $* * *$ & & & $* *$ & & $* *$ & \\
\hline AG (BA 39) & & & & $* * *$ & & & & & & & & \\
\hline PPC/SPL (BA 7) & & $* * *$ & $* * *$ & & & & & & & & & \\
\hline PCC (BA 31) & & & & & $* * *$ & $* * *$ & & & & & & $* *$ \\
\hline DLPFC (BA 46, 9) & & & $* * *$ & $* *$ & & & & & & & & \\
\hline VLPFC (BA 45, 47) & & $* *$ & & & & & & & & $* * *$ & & \\
\hline mOFC (BA 11) & & $* *$ & & & & $* * *$ & & & $* * *$ & $* * *$ & & \\
\hline dACC (BA 32) & & & $* * *$ & & $* * *$ & $* * *$ & & & & & & $* *$ \\
\hline TP (BA 38) & & $* * *$ & $* *$ & & $* * *$ & $* * *$ & & & $* * *$ & & $* * *$ & $* * *$ \\
\hline MVT (BA28, 35, 36) & & $* * *$ & & $* * *$ & $* * *$ & & & $* * *$ & & $* * *$ & & \\
\hline STS (BA 21) & & & & & & & & & & $* *$ & $* * *$ & \\
\hline
\end{tabular}

The symbols are the same as in Table 1

(FP, BA 10), TP, and left hippocampus. At $\sim 300 \mathrm{~ms}$, the typical latency for the $\mathrm{P} 300$, the schizophrenia group showed hypoactivation in S1, S2, vPMA, PCL, STS, mOFC, insula, and the ventral aspect of TP but hyperactivation in $\mathrm{AG}$ and FP. At $\sim 450 \mathrm{~ms}$, whereas S2, M1, mOFC, and the anterior aspect of insula showed hypoactivation in people with schizophrenia, vOFC, STS, posterior aspect of insula, anterior ventral temporal lobe (BA 22), and TP showed hyperactivations. The ACC showed some interesting activity patterns: whereas the control group showed more activation than the schizophrenia group in dorsal ACC, the schizophrenia group showed more activation than controls in rostral and ventral ACC. The above results are also summarized in the middle columns of Table 3 for the most commonly activated sources.

\section{Abnormal Attention-related Activations in Left \\ Hemisphere due to Ipsilateral Stimuli in Schizophrenia Versus Controls}

Figure $4 \mathrm{~b}$ and the right columns of Table 3 show group differences in left hemisphere attention-related (rare-frequent difference) activation evoked by the ipsilateral median-nerve stimulation. At $\sim 40$ and $\sim 80 \mathrm{~ms}$, the only group difference was hyperactivation in the TP area in the schizophrenia group. At later latencies, the schizophrenia group showed persistent hypoactivation in S1, S2, DLPFC, and MVT areas but hyperactivation in vACC and mOFC. The SPL and STS areas in the patient group exhibited hypoactivation at $\sim 220 \mathrm{~ms}$ and at $\sim 450 \mathrm{~ms}$, respectively, and the vPMA showed hyperactivation at $\sim 140 \mathrm{~ms}$. The left TP areas in the patient group showed early $(\sim 40$ $220 \mathrm{~ms})$ hyper- but later ( $\sim 300-450 \mathrm{~ms})$ hypoactivation.

Abnormal Attention-related Activations in Right

Hemisphere due to Contralateral Stimuli in

Schizophrenia Versus Controls

Figure $4 \mathrm{c}$ and the middle columns of Table 4 show group differences in right-hemisphere attention-related (rare-frequent difference) activation evoked by contralateral (left) median-nerve stimulation. The overall patterns of hypoand hyperactivation in the right-hemisphere evoked by contralateral stimuli were similar to those in the left hemisphere (Fig. 4a). At $\sim 40 \mathrm{~ms}$, the schizophrenia group showed hyperactivation in S1, M1, and vPMA, but hypoactivation in dPMA. At $\sim 80 \mathrm{~ms}$, the schizophrenia group showed hypoactivation in S1, S2, M1, dPMA, SMG/ILP, PPC/SPL, VLPFC, and mOFC but hyperactivation in PCL. A medial aspect of MVT showed hypoactivation, whereas a more lateral aspect of the same area showed hyperactivation. At $\sim 140 \mathrm{~ms}$, the schizophrenia group showed 
Fig. 4 Group differences in attention-related brain activation (rare minus frequent responses). a Left-hemisphere group differences in activation, evoked by contralateral (right arm) median-nerve stimulation. b Left-hemisphere group differences in activation, evoked by ipsilateral stimulation (left arm). c Righthemisphere group differences in activation, evoked by contralateral stimulation (left arm). d Right-hemisphere group differences in activation, evoked by ipsilateral stimulation (right arm). FWER is controlled at $P=.05$ level. The red-yellow color indicates statistically stronger activation in the control group than in the patient group (hypo-activation for the patients), whereas the blue-cyan color indicates stronger activation in the patient than control group (hyperactivation for the patients)

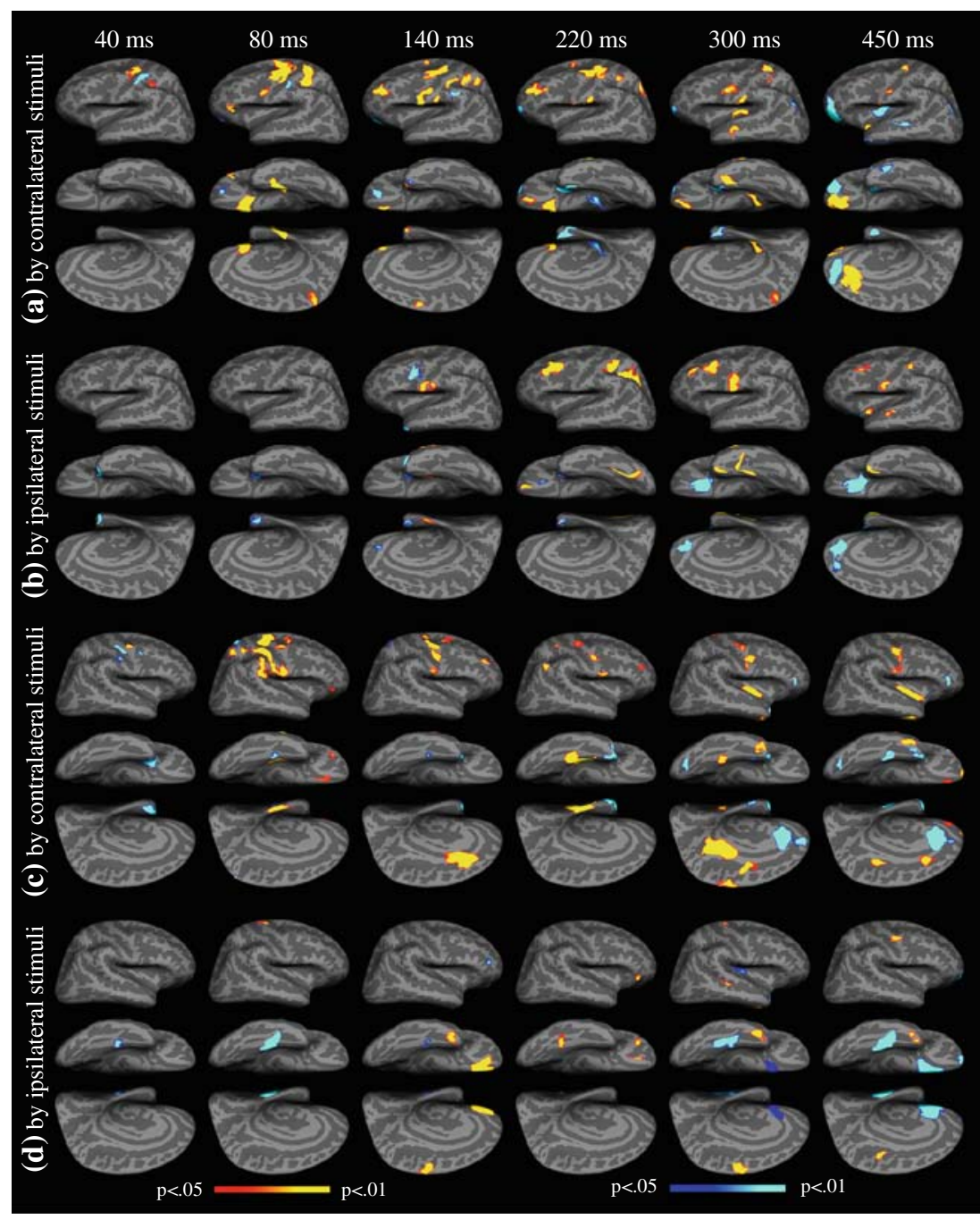

hypoactivation in S2, M1, and DLPFC but hyperactivation in PCL, TP, and MVT. At $\sim 220 \mathrm{~ms}$, the schizophrenia group showed hypoactivation in S1, M1, vPMA, AG, DLPFC, and MVT, but hyperactivation in TP. At $\sim 300 \mathrm{~ms}$, the schizophrenia group showed hypoactivation in S2, M1, SMA, PCC, dACC, MVT, and insula but hyperactivation in VLPFC, VACC, and MVT. The lateral aspect of the TP showed hypoactivation, whereas the medial aspect of the same area showed hype-activation. At $\sim 450 \mathrm{~ms}$, the schizophrenia group showed hypoactivation in S2, M1, PCC, VLPFC, mOFC, FP, dACC, and insula but hyperactivation in VLPFC, vACC, and MVT. The TP still showed mixed activation, similar to $\sim 300 \mathrm{~ms}$.

Abnormal Attention-related Activations in Right Hemisphere due to Ipsilateral Stimuli in Schizophrenia Versus Controls

Finally, for Fig. 4d the columns of Table 4 show group differences in the right-hemisphere attention-related activation evoked by the ipsilateral (right) median-nerve stimulation. Whereas the MVT showed hyperactivation at $\sim 40$ and $\sim 80 \mathrm{~ms}$ in the schizophrenia group, the dPMA showed hypoactivation at $\sim 80 \mathrm{~ms}$. At $\sim 140 \mathrm{~ms}$, the schizophrenia group showed hypoactivation in SMA, mOFC, and TP but hyperactivation in VLPFC and MVT. At $\sim 220 \mathrm{~ms}$, the schizophrenia group showed hypoactivation in VLPFC, mOFC, and MVT. At $\sim 300 \mathrm{~ms}$, hypoactivation was observed in IPMA, SMA, TP, and STS in the schizophrenia group, whereas mOFC, MVT, and insula exhibited hypoactivation. At $\sim 450 \mathrm{~ms}$, the schizophrenia group exhibited hypoactivation in M1 and $\mathrm{TP}$, whereas hyperactivation was seen in mOFC, FP, vACC, and MVT.

Activation maps for within-schizophrenia-group poststimulus versus pre-stimulus comparison would be redundant and are not shown. Instead, both the pre- and post-stimulus activation maps in healthy controls and the maps that showed group differences between healthy controls and schizophrenia patients have been presented. 
Table 3 Left hemisphere group differences to stimuli delivered to the contralateral and ipsilateral median-nerves

\begin{tabular}{|c|c|c|c|c|c|c|c|c|c|c|c|c|}
\hline \multirow[t]{2}{*}{$\begin{array}{l}\text { Source/latency (ms) } \\
\text { (m) }\end{array}$} & \multicolumn{6}{|c|}{ Contralateral stimuli } & \multicolumn{6}{|c|}{ Ipsilateral stimuli } \\
\hline & 40 & 80 & 140 & 220 & 300 & 450 & 40 & 80 & 140 & 220 & 300 & 450 \\
\hline $\mathrm{S} 1$ (BA 3b, 1, 2) & $\uparrow \uparrow$ & $?$ & $\downarrow \downarrow$ & $\downarrow \downarrow$ & $\downarrow \downarrow$ & & & & & $\downarrow \downarrow$ & & $\downarrow \downarrow$ \\
\hline S2 (BA 43, 40) & & & $\downarrow \downarrow$ & $\downarrow \downarrow$ & $\downarrow \downarrow$ & $\downarrow$ & & & $\downarrow \downarrow$ & & $\downarrow \downarrow$ & $\downarrow \downarrow$ \\
\hline M1 (BA 4) & $\downarrow \downarrow$ & $\downarrow \downarrow$ & $\downarrow \downarrow$ & $\downarrow \downarrow$ & & $\downarrow \downarrow$ & & & & & & \\
\hline dPMA (BA 6) & $\downarrow \downarrow$ & $\downarrow \downarrow$ & $\downarrow \downarrow$ & $\downarrow \downarrow$ & & & & & & & & \\
\hline vPMA (BA 6) & & $\downarrow \downarrow$ & $\downarrow \downarrow$ & & $\downarrow \downarrow$ & & & & $\uparrow \uparrow$ & & & \\
\hline PCL (BA 5) & & $\downarrow \downarrow$ & & & $\downarrow \downarrow$ & & & & & & & \\
\hline SMA (BA 6) & & & $\downarrow \downarrow$ & & & & & & & & & \\
\hline Insula & & & & & $\downarrow \downarrow$ & $?$ & & & & & & $\downarrow \downarrow$ \\
\hline SMG/IPL (BA 40) & & & $\uparrow \uparrow$ & & & & & & & & & \\
\hline AG (BA 39) & & & & & $\uparrow \uparrow$ & $\uparrow$ & & & & & & \\
\hline PPC/SPL (BA 7) & $\downarrow$ & $\downarrow \downarrow$ & $\downarrow \downarrow$ & $\downarrow \downarrow$ & $\downarrow$ & & & & & $\downarrow \downarrow$ & & \\
\hline PCC (BA 31) & & & & & & & & & & & & \\
\hline DLPFC (BA 46, 9) & & & $\downarrow \downarrow$ & $\downarrow \downarrow$ & & $\downarrow$ & & & & $\downarrow \downarrow$ & $\downarrow \downarrow$ & $\downarrow \downarrow$ \\
\hline VLPFC (BA 45, 47) & & $\downarrow \downarrow$ & & & & & & & & & & \\
\hline mOFC (BA 11) & & $\downarrow \downarrow$ & $\downarrow \downarrow$ & $\downarrow \downarrow$ & $\downarrow \downarrow$ & $\downarrow \downarrow$ & & & & $?$ & $\uparrow \uparrow$ & $\uparrow \uparrow$ \\
\hline vOFC (BA 11, 47) & & $\uparrow \uparrow$ & $\uparrow \uparrow$ & & & $\uparrow \uparrow$ & & & & & & \\
\hline FP (BA 10) & & & & $\uparrow \uparrow$ & $\uparrow \uparrow$ & $\uparrow \uparrow$ & & & & & & \\
\hline dACC (BA 32) & & & & & & $\downarrow \downarrow$ & & & & & & \\
\hline vACC (BA 32) & & & & & & $\uparrow \uparrow$ & & & $\uparrow$ & & $\uparrow \uparrow$ & $\uparrow \uparrow$ \\
\hline TP (BA 38) & & & $?$ & $\uparrow \uparrow$ & $?$ & $\uparrow \uparrow$ & $\uparrow \uparrow$ & $\uparrow \uparrow$ & $\uparrow \uparrow$ & $\uparrow$ & $\downarrow \downarrow$ & $\downarrow \downarrow$ \\
\hline MVT (BA28, 35, 36) & & $\downarrow \downarrow$ & & & & & & & $\downarrow \downarrow$ & & $\downarrow \downarrow$ & \\
\hline STS (BA 21) & & & & & $\downarrow \downarrow$ & $\uparrow \uparrow$ & & & & & & $\downarrow \downarrow$ \\
\hline
\end{tabular}

The $\downarrow$ and $\downarrow \downarrow$ indicate that the schizophrenia group had less (hypo-) activation than the control group with $P<.05$ and $P<.01$, respectively. The $\uparrow$ and $\uparrow \uparrow$ indicate that the schizophrenia group has more (hyper-) activation than the control group with $P<.05$ and $P<.01$, respectively. The "?" indicates that one aspect of the area shows hyper-activation whereas the other aspect of the same area shows hypo-activation

The activation maps in schizophrenia patients can be readily inferred from the two maps that provided.

\section{Discussion}

The major findings in the present MEG study can be grouped into two categories. The first category involves the neuronal networks activated by the attention-related somatosensory task using median-nerve oddball stimuli in healthy subjects. The second category involves the deficits related to these neuronal networks in individuals with schizophrenia. In healthy control subjects, MEG results obtained from the VESTAL high-resolution imaging approach (Fig. 3; Tables 1,2) showed that two major networks were activated: (1) a sensorimotor network and (2) a frontal-parietaltemporal attention network. The former is modality-specific to somatosensory stimulation, whereas, as discussed below, the latter is likely modality-independent. The MEG results showed that all cortical areas in the sensorimotor network, namely S1, S2, M1, dorsal pre-motor area (dPMA), ventral pre-motor area (vPMA), supplementary motor area (SMA), and paracentral lobule (PCL), were sensitive to attention to somatosensory stimulation but at different times. The high temporal resolution of MEG also showed that the earliest attention-related responses started at $\sim 40 \mathrm{~ms}$; the strong earlier $\mathrm{N} 20 \mathrm{~m}$ and $\mathrm{P} 30 \mathrm{~m}$ components at $\sim 20-30 \mathrm{~ms}$, respectively, were not sensitive to attention modulation, a finding consistent with previous EEG and MEG findings (Waberski et al. 2002; Huang et al. 2005). Since these very early components (particularly N20m) are evoked through direct projections from thalamus to $\mathrm{S} 1$ and $\mathrm{M} 1$ areas, their lack of attention-related activation is consistent with the theory that the attention modulation is from the prefrontal lobe (Gazzaley and D'Esposito 2008), not directly from the thalamus.

Attention-related Activations of Sensorimotor Network in Healthy Controls

MEG results also showed that, within the sensorimotor network, attention-related activations in S1, M1, and dPMA preceded activation in other cortical areas (i.e., S2, vPMA, PCL, SMA, and insula), indicating attention-related 
Table 4 Group differences in the right hemisphere evoked by stimuli delivered to the contralateral and ipsilateral median-nerves

\begin{tabular}{|c|c|c|c|c|c|c|c|c|c|c|c|c|}
\hline \multirow[b]{2}{*}{ Source/latency (ms) } & \multicolumn{6}{|c|}{ Contralateral stimuli } & \multicolumn{6}{|c|}{ Ipsilateral stimuli } \\
\hline & 40 & 80 & 140 & 220 & 300 & 450 & 40 & 80 & 140 & 220 & 300 & 450 \\
\hline $\mathrm{S} 1$ (BA 3b, 1, 2) & $\uparrow \uparrow$ & $\downarrow \downarrow$ & & $\downarrow$ & & & & & & & & \\
\hline S2 (BA 43, 40) & & $\downarrow \downarrow$ & $\downarrow \downarrow$ & & $\downarrow$ & $\downarrow \downarrow$ & & & & & & \\
\hline M1 (BA 4) & $\uparrow \uparrow$ & $\downarrow \downarrow$ & $\downarrow \downarrow$ & $\downarrow \downarrow$ & $\downarrow$ & $\downarrow \downarrow$ & & & & & & $\downarrow \downarrow$ \\
\hline dPMA (BA 6) & $\downarrow \downarrow$ & $\downarrow \downarrow$ & & & & & & $\downarrow \downarrow$ & & & $\downarrow \downarrow$ & \\
\hline vPMA (BA 6) & $\uparrow \uparrow$ & & & $\downarrow \downarrow$ & & & & & & & & \\
\hline PCL (BA 5) & & $\uparrow \uparrow$ & $\uparrow$ & & & & & & & & & \\
\hline SMA (BA 6) & & & & & $\downarrow \downarrow$ & & & & $\downarrow \downarrow$ & & $\downarrow \downarrow$ & \\
\hline Insula & & & & & $\downarrow \downarrow$ & $\downarrow \downarrow$ & & & & & $\uparrow$ & \\
\hline SMG/IPL (BA 40) & & $\downarrow \downarrow$ & & & & & & & & & & \\
\hline AG (BA 39) & & & & $\downarrow \downarrow$ & & & & & & & & \\
\hline PPC/SPL (BA 7) & & $\downarrow \downarrow$ & & & & & & & & & & \\
\hline PCC (BA 31) & & & & & $\downarrow \downarrow$ & $\downarrow \downarrow$ & & & & & & \\
\hline DLPFC (BA 46, 9) & & & $\downarrow \downarrow$ & $\downarrow$ & & & & & & & & \\
\hline VLPFC (BA 45, 47) & & $\downarrow \downarrow$ & & & $\uparrow \uparrow$ & $\uparrow \uparrow$ & & & $\uparrow \uparrow$ & $\downarrow \downarrow$ & & \\
\hline mOFC (BA 11) & & $\downarrow$ & & & & $\downarrow$ & & & $\downarrow \downarrow$ & $\downarrow$ & $\uparrow$ & $\uparrow \uparrow$ \\
\hline vOFC (BA 11, 47) & & & & & & & & & & & & \\
\hline FP (BA 10) & & & & & & $\downarrow \downarrow$ & & & & & & $\uparrow \uparrow$ \\
\hline dACC (BA 32) & & & $\downarrow \downarrow$ & & $\downarrow \downarrow$ & $\downarrow \downarrow$ & & & & & & \\
\hline vACC (BA 32) & & & & & $\uparrow \uparrow$ & $\uparrow \uparrow$ & & & & & & $\uparrow \uparrow$ \\
\hline TP (BA 38) & & & $\uparrow \uparrow$ & $\uparrow \uparrow$ & $?$ & $?$ & & & $\downarrow \downarrow$ & & $\downarrow \downarrow$ & $\downarrow \downarrow$ \\
\hline MVT (BA28, 35, 36) & & $?$ & $\uparrow$ & $\downarrow \downarrow$ & $\uparrow \uparrow$ & $\uparrow \uparrow$ & $\uparrow \uparrow$ & $\uparrow \uparrow$ & $\uparrow$ & $\downarrow \downarrow$ & $\uparrow \uparrow$ & $\uparrow \uparrow$ \\
\hline STS (BA 21) & & & & & & & & & & & $\downarrow \downarrow$ & \\
\hline
\end{tabular}

The symbols are the same as in Table 3

information processing from primary to secondary sensorimotor areas. In addition, activation in the somatosensorymotor network evoked by stimuli delivered to the contralateral wrist were stronger in amplitude and earlier in latency than those evoked by ipsilateral stimuli, indicating a sequence of activation from the contralateral to ipsilateral hemisphere. The attention-related activation in S1, S2, M1, and PMA obtained from VESTAL in the present study is consistent with previous results using a multiple-dipole-fit approach (Huang et al. 2005). Similarly, attention-related activation to somatosensory stimulation has been reported in S2 (Mima et al. 1998; Backes et al. 2000; Waberski et al. 2002) and S1 (Waberski et al. 2002). The sequence of sensorimotor activation in the present study, however, lends support to the concept of a sequential somatosensory pathway from S1 via S2 to insula (Mishkin 1979; Friedman et al. 1986).

\section{Attention-related Activations of Posterior Parietal Areas in Healthy Controls}

Control subjects also showed activation in a distributed frontal-parietal-temporal network when attending to somatosensory stimuli. The key areas in the posterior parietal lobe were supramarginal gyrus/inferior parietal lobule (SMG/IPL), dorsal posterior parietal cortex/superior parietal lobule (dPPC/SPL), and angular gyrus (AG) (albeit only briefly). The locations of these activations are consistent with ERP and fMRI studies using auditory or visual oddball tasks. ERP studies using scalp, intracranial, or depth recordings with auditory or visual oddball paradigms showed activation in multiple parietal regions, including bilateral posterior parietal areas (Halgren et al. 1995a; Turetsky et al. 1998; He et al. 2001; Turetsky et al. 2004), the lateral and inferior parietal cortex (Smith et al. 1990; Anderer et al. 1998; Halgren et al. 1998), and the parietaloccipital junction (Kiss et al. 1989; Anderer et al. 1998; Wang et al. 2003). Activation in the SMG/IPL has also been consistently reported in fMRI studies using auditory and visual oddball tasks (McCarthy et al. 1997; Menon et al. 1997; Linden et al. 1999; Yoshiura et al. 1999; Clark et al. 2000; Stevens et al. 2000; Kiehl and Liddle 2001; Ardekani et al. 2002). Despite this consistency in source location, the latencies of parietal activation in the present study (i.e., onset latencies at $\sim 40$ or $80 \mathrm{~ms}$ for SMG/IPL and dPPC/SPL) were markedly earlier than those seen in ERP studies of the P300 component in the context of auditory and visual oddball tasks. The earlier posterior 
parietal activation for somatosensory oddball task versus auditory and visual oddball stimuli might be partly explained by the fact that these parietal regions (BA 7 for dPPC/SPL and BA 40 for SMG/IPL) are anatomically adjacent to primary somatosensory areas (BA 1 and 2) and secondary somatosensory areas (BA 43 and anterior aspect of BA 40). Another contribution to the increased latency of the effects in auditory and visual oddball tasks compared to somatosensory parietal oddball activation is due to the long processing time in auditory and visual cortices (e.g. $50 \mathrm{~ms}$ and $80 \mathrm{~ms}$ ) compared to somatosensory cortex (20 ms).

Present results also showed that activation in posterior parietal areas evoked by contralateral median-nerve stimuli was markedly earlier (at least $60 \mathrm{~ms}$ ) than that evoked by ipsilateral stimuli. In some posterior parietal regions, the activation evoked by ipsilateral stimuli either did not reach a statistically significant level (e.g. left SMG/IPL and right $\mathrm{dPPC} / \mathrm{SPL}$ ) or was greatly reduced (e.g., left SMG/IPL) compared with the same parietal sources evoked by contralateral stimuli.

\section{Attention-related Activations of Prefrontal Areas in Healthy Controls}

In frontal lobe structures, the key areas showing reliable attention-related activation during the median-nerve oddball task were DLPFC, VLPFC, the medial aspect of OFC, and the dorsal aspect of anterior ACC. The locations of this frontal activity are consistent with findings from ERP and fMRI auditory or visual oddball studies. Specifically, activation in DLPFC, ACC, and OFC has been consistently reported in scalp or intracranial P300 studies (Simson et al. 1976; Snyder et al. 1980; Yingling and Hosobuchi 1984; McCarthy and Wood 1987; Smith et al. 1990; Neshige and Luders 1992; Baudena et al. 1995; Anderer et al. 1998; Turetsky et al. 1998; Halgren et al. 1998; Wang et al. 2003; Turetsky et al. 2004). In addition, activation in DLPFC and middle frontal gyrus (MFG) and ACC has frequently been reported in fMRI studies using auditory and visual oddball tasks (McCarthy et al. 1997; Menon et al. 1997; Linden et al. 1999; Yoshiura et al. 1999; Clark et al. 2000; Stevens et al. 2000; Kiehl and Liddle 2001; Ardekani et al. 2002). Similar to the posterior parietal activation, the onset of frontal activation in the present study (e.g., onset $\sim 80 \mathrm{~ms}$ for VLPFC and $\sim 140 \mathrm{~ms}$ for DLPFC) was also markedly earlier than those seen in previous ERP P300 studies using auditory and visual oddball tasks, indicating modality-specific differences.

Attention-related Activations of Temporal Areas in Healthy Controls

In the temporal lobe, the key areas activated were temporal pole (TP), medioventral temporal lobe (MVT), superior temporal sulcus (STS), and hippocampus. These results are highly consistent with the temporal lobe activation observed in many scalp or intracranial ERP auditory or visual P300 studies (Halgren et al. 1980; Stapleton and Halgren 1987; Lovrich et al. 1988; Kiss et al. 1989; Knight et al. 1989; Neshige and Luders 1992; O'Donnell et al. 1993; Tarkka et al. 1995; Halgren et al. 1995a, b, 1998; Hegerl and Frodl-Bauch 1997; Wang et al. 2003). These temporal lobe activations, particularly the ventral temporal regions, are usually not observed in fMRI studies during auditory and visual oddball tasks, likely the result of large susceptibility artifacts in that region. Although there has been debate whether MEG can reliably localize signal from hippocampus, compelling evidence that this can be done is available. Hippocampal activations have been reported in MEG studies using dSPM (Dale et al. 2000) and spatialtemporal multiple dipole modeling techniques (Hanlon et al. 2003). Our MEG system with a combination of gradiometer (sensitive to cortical activations) and magnetometers (sensitive to both cortical and sub-cortical activations) may also have contributed to our observation of signals from hippocampus.

\section{Attention Deficits of Sensorimotor Network} in Schizophrenia

Schizophrenic patients exhibited abnormalities in both the sensorimotor and the frontal-parietal-temporal attention network (Fig. 4; Tables 3, 4). To our knowledge, this is the first functional imaging study that systematically examined attention-related deficits using somatosensory stimuli in schizophrenia. Within the sensorimotor network, reduced (hypo-) attention-related activation was observed in S2 and dorsal pre-motor areas (dPMA) in schizophrenia patients in both hemispheres, across all latencies, and to both contralateral and ipsilateral stimuli. S2 is crucial in higher-order somatosensory perception including somatosensory-specific attention, learning, integration, discrimination and memory (Ridley and Ettlinger 1978; Burton 1986; Caselli 1993). The dPMA exhibits a far more complex relationship with movement characteristics than M1. Unlike M1, activation in dPMA is more sensitive to movement-related conditional cues (Kurata and Hoffman 1994) and sequence-specific properties of movement (Kurata 1991; Mushiake et al. 1991; Kettner et al. 1996; Harrington et al. 2000). dPMA activation also is associated with the complexity of planning movements (Sadato et al. 1996; Catalan et al. 1998; Dassonville et al. 1998; Solodkin et al. 2001), whereas M1 activation can usually be attributed to an increase in the number of active muscle groups (Rao et al. 1993; Shibasaki et al. 1993; Wexler et al. 1997; Gordon et al. 1998; Solodkin et al. 2001). Reduced S2 and dPMA activation in schizophrenia patients may be the 
main cause of difficulties in somatosensory discrimination and somatosensory feedback to prepare and guide hand movements.

Another important finding in the sensorimotor network in schizophrenia patients was the early hyper-activation in S1 (in both hemispheres) and M1 (in right hemisphere) at $\sim 40 \mathrm{~ms}$ in the attention-related MEG responses evoked by contralateral median-nerve stimuli, followed by hypoactivation in these areas throughout the remaining poststimulus interval for both contralateral and ipsilateral stimulation. In lesion studies, S1 has been shown to be indispensable for somatosensory perception (Randolph and Semmes 1974; Carlson 1981). M1, on the other hand, is well-known for its crucial role in motor execution (Kandel et al. 2000). M1 also receives afferent sensory input from peripheral neurons, albeit weaker than $\mathrm{S} 1$ (see review of literature in (Huang et al. 2000; Huang et al. 2004a)). Early hyper-activation in S1 and M1 may be due to a lack of inhibition in these areas in schizophrenia patients. Hypoactivation in S1 and M1 at later latencies in schizophrenic patients may be explained by the reduced interaction between primary sensorimotor areas and higher-order somatosensory and motor processing areas such as S2 and dPMA, in which hypoactivation was persistent in both hemispheres across all latencies. Finally, it is worth noting that present findings are consistent with other somatosensory studies observing intact early M20 somatosensory activity (Edgar et al. 2005) but impaired secondary somatosensory cortex activity at $\sim 80 \mathrm{~ms}$ (Thoma et al. 2007) in patients with schizophrenia.

\section{Attention-related Abnormalities of DLPFC in Schizophrenia}

Schizophrenic patients also showed abnormalities in the frontal-parietal-temporal attention network. One key finding was hypo-activation of DLPFC to contralateral stimulation, seen in both hemispheres at 140-220 ms. Although these time intervals coincide with the typical interval for MMN in studies of auditory attention, reduced DLPFC activation in the present study is not likely related to reduced MMN in the auditory modality, because auditory MMN deficits in schizophrenia have been shown to originate in auditory cortex in the superior temporal lobe (Thonnessen et al. 2008), and we know of no published studies showing reduced DLPFC activation in auditory MMN. It is more likely that the reduced DLPFC activation during the 140-220 ms interval in the present study is analogous to the hypo-activation found in DLPFC for the P300 component using auditory and visual stimuli in individuals with schizophrenia (Pritchard 1986; Pfefferbaum et al. 1989; Ford et al. 1992; Polich and Kok 1995; Andreasen 1999). In present study, the markedly earlier onset (i.e., $\sim 140 \mathrm{~ms}$ ) of the DLPFC hypoactivation in schizophrenic patients may be unique to the somatosensory modality, since it has not been reported previously. Because DLPFC is crucial for modulating executive functions, DLPFC hypo-activation is also consistent with similar findings in studies of working memory deficits in schizophrenia (for a review see (Barch 2005)).

Attention-related Abnormalities of Parietal Areas in Schizophrenia

Another key finding was hypo-activation in patients in the dorsal posterior parietal cortex/superior parietal lobule (dPPC/SPL), which was evoked by contralateral stimulation and was long-lasting in the left hemisphere (40-300 ms) but brief in the right hemisphere $(\sim 80 \mathrm{~ms})$. This finding suggests that the dPPC/SPL abnormality in schizophrenia is predominantly in the left hemisphere. Dorsal posterior parietal cortex is ideally situated to receive multimodalsensory inputs. As such, it plays a crucial role in many behaviors including the control of goal-directed actions of the limbs and eyes, visuospatial attention, and corporeal awareness (Goodale and Milner 1992; Berlucchi and Aglioti 1997; Wojciulik et al. 1998; Corbetta 1998; Blakemore and Frith 2003). Interestingly, in most etiological models of schizophrenia, relatively little discussion is devoted to a possible role for the posterior parietal cortex (Danckert et al. 2004). The reduced dPPC/SPL activation observed here in the context of somatosensory attention is consistent with the theory that patients experiencing passivity phenomena (e.g., delusions of control) have particular impairments of parietal function related to poor utilization of forward models of intended actions (Danckert et al. 2004).

Unlike hypo-activation in bilateral dPPC/SPL, schizophrenic patients showed hyperactivation in the left inferior parietal lobe (IPL/SMG at $~ 140$ and angular gyrus (AG) at $\sim 300-450 \mathrm{~ms}$ ), yet hypo-activation in the right inferior parietal lobe (IPL/SMG at $\sim 80 \mathrm{~ms}$ and AG at $\sim 220 \mathrm{~ms}$ ). This finding may be explained by compensatory recruitment of alternative regions due to lost or impaired function in other areas. In particular, IPL/SMG and AG are very close to S2 (anterior aspect of BA 40) and dPPC/SPL (BA 7) and may be positioned to compensate for S2 and PPC/ SPL dysfunction. This explanation is supported by the fact that hyper-activation in the left IPL/SMG and AG coincided with persistent hypo-activation in left $\mathrm{S} 2$ and $\mathrm{dPPC} /$ SPL across the post-stimulus interval.

Attention-related Abnormalities of ACC, OFC, and FP in Schizophrenia

Possible compensatory recruitment of alternative areas in schizophrenia patients may also have been observed in 
frontal areas, such as anterior cingulated cortex (ACC) and orbitofrontal cortex (OFC). In healthy controls, the dorsal aspect of the ACC showed robust attention-related activation in the left and right hemispheres following contralateral median-nerve stimuli. In contrast, the schizophrenia patients showed diminished dACC, but hyper-activation in the ventral aspect of ACC (vACC), in both hemispheres. In the left OFC in schizophrenia patients, the medial aspect of this area showed reduced attention-related activation from $\sim 80$ to $\sim 450 \mathrm{~ms}$, but hyper-activation in the more lateralventral aspect of the OFC or nearby frontal pole (FP). In the right $\mathrm{OFC}$, the patient group showed reduced mOFC activation at an earlier latency $\sim 140 \mathrm{~ms}$, but hyper-activation in the same region at the later 300-450 ms interval (ipsilateral evoked), indicating delayed activation with respect to the controls.

Present findings of a coexistence of hypo- and hyperactivations in ACC raise interesting questions about the relationship between deficits in ACC and DLPFC function in schizophrenia. Currently there are three models that explain the functional relationship between DLPFC and ACC, namely the cascade-of-control theory, conflicting-monitoring theory, and the error-detection theory (see reviews in Barch 2005; Banich et al. 2009)). Impaired DLPFC function leading to increased conflict and errors might predict increased ACC activation in individuals with schizophrenia, according to the conflict-monitoring theory (ACC activity is elicited by more conflict and errors). However, impaired DLPFC function might predict reduced ACC activity according to the error-detection theory, if reduced DLPFC activity reflects degraded representations of the predictive information needed to drive an error-correcting signal that in turn elicits ACC activity. Present findings suggest that different portions of the ACC may play different roles in explaining cognitive deficits in schizophrenia-the hyperactivation of the ventral aspect of ACC is consistent with the prediction of the conflict-monitoring theory, whereas the hypo-activation of the dorsal aspect of ACC is consistent with error-detection theory predictions. Additional regional functional specificity in these structures may be relevant (Banich et al. 2009).

Attention-related Abnormalities of Temporal Areas in Schizophrenia

Complicated patterns of group differences in temporal lobe areas were observed. The most consistent finding was that patients with schizophrenia showed hyper-activation in the medial aspect of the temporal pole (TP) versus hypo-activation in the ventral aspect of the TP. The right medioventral temporal lobe (MVT) also showed mixed hypo- and hyper-activation in patients. These temporal lobe areas play important roles in the encoding and recognition of sensory representations of semantic and episodic information and visuospatial learning and memory (Nyffeler et al. 2005). The co-existence of hypo- and hyper-activations in different temporal lobe areas may reflect a complicated compensatory mnemonic strategy in schizophrenia patients for attending to the rare stimuli while ignoring the frequency stimuli.

\section{Summary of the Study}

In summary, two neuronal networks were activated with substantial overlap in time in the healthy control participants. The first was a modality-specific sensorimotor network including S1, S2, M1, PMA, PCL, SMA, and insula. The second was an attention network that included the frontal lobe (i.e., LPFC, OFC, and ACC), parietal lobe (i.e., SMG/ILP, dPPC/SPL, and posterior cingulate cortex (PCC)), and temporal lobe (TP, MVT, and STS). We speculate that the relevant areas in the attention network may be supramodal since they are typically activated during auditory and visual attention tasks, although the onset of this attention network activation response for somatosensory stimuli was earlier than for auditory and visual stimuli. The apparent modality-independence of activation in the frontal-parietal-temporal network may represent an important cortical network in early processing stages of working memory (McCarthy et al. 1997; Halgren et al. 1998). This is supported by physiological studies in monkeys (Baddeley 1992) and neuroimaging studies in humans (Cohen et al. 1994; McCarthy et al. 1994, 1996; Smith and Jonides 1997), which reveal a similar network supporting cognitive operations involved in working memory.

The present study also showed profound attention-related deficits in both the sensorimotor and frontal-parietaltemporal networks using somatosensory stimuli. Patients with schizophrenia showed early attention-related hyperactivation in S1 and M1, and then later hypo-activation in $\mathrm{S} 1, \mathrm{~S} 2, \mathrm{M} 1$, and PMA in the sensorimotor network. Within the frontal-parietal-temporal attention network, hypoactivation was found in SPL, DLPFC, orbitofrontal cortex, and the dorsal aspect of ACC. Hyperactivation was seen in SMG/IPL, frontal pole, and the ventral aspect of ACC in patients. These findings link attention-related somatosensory deficits to dysfunction in both sensorimotor and frontal-parietal-temporal networks in schizophrenia. Present findings thus provide a starting point for a model of somatosensory dysfunction in schizophrenia that can help guide the development of treatments to reduce somatosensory-related cognitive deficits and to improve quality of life for these individuals.

Acknowledgments This work was supported in part by several Merit Review Grants from the Department of Veterans Affairs to 
Dr. Huang (051455 and 060812), Dr. Granholm, Dr. Harrington (104279 and B5015-R), and Dr. Lee (E4477-R), and an NIMH R01 grant (R01-MH071410) to Dr. Granholm. We would also like to thank two anonymous reviewers' constructive suggestions that substantially strengthen the present study.

Open Access This article is distributed under the terms of the Creative Commons Attribution Noncommercial License which permits any noncommercial use, distribution, and reproduction in any medium, provided the original author(s) and source are credited.

\section{References}

Achim A (2001) Statistical detection of between-group differences in event-related potentials. Clin Neurophysiol 112:1023-1034

Alain C, Hargrave R, Woods DL (1998) Processing of auditory stimuli during visual attention in patients with schizophrenia. Biol Psychiatry 44:1151-1159

Alho K (1995) Cerebral generators of mismatch negativity (MMN) and its magnetic counterpart (MMNm) elicited by sound changes. Ear Hear 16:38-51

Anderer P, Pascual-Marqui RD, Semlitsch HV, Saletu B (1998) Differential effects of normal aging on sources of standard N1, target N1 and target P300 auditory event-related brain potentials revealed by low resolution electromagnetic tomography (LORETA). Electroencephalogr Clin Neurophysiol 108:160-174

Andreasen NC (1999) A unitary model of schizophrenia: Bleuler's "fragmented phrene" as schizencephaly. Arch Gen Psychiatry 56:781-787

Ardekani BA, Choi SJ, Hossein-Zadeh GA, Porjesz B, Tanabe JL, Lim KO, Bilder R, Helpern JA, Begleiter H (2002) Functional magnetic resonance imaging of brain activity in the visual oddball task. Brain Res Cogn Brain Res 14:347-356

Asanuma H, Larsen K, Yumiya H (1980) Peripheral input pathways to the monkey motor cortex. Exp Brain Res 38:349-355

Backes WH, Mess WH, van Kranen-Mastenbroek V, Reulen JP (2000) Somatosensory cortex responses to median nerve stimulation: fMRI effects of current amplitude and selective attention. Clin Neurophysiol 111:1738-1744

Baddeley A (1992) Working memory. Science 255:556-559

Baldissera F, Leocani L (1995) Afferent excitation of human motor cortex as revealed by enhancement of direct cortico-spinal actions on motoneurones. Electroencephalogr Clin Neurophysiol 97:394-401

Banich MT, Mackiewicz KL, Depue BE, Whitmer AJ, Miller GA, Heller W (2009) Cognitive control mechanisms, emotion and memory: a neural perspective with implications for psychopathology. Neurosci Biobehav Rev 33:613-630

Barch DM (2005) The cognitive neuroscience of schizophrenia. Annu Rev Clin Psychol 1:321-353

Barnes GR, Hillebrand A (2003) Statistical flattening of MEG beamformer images. Hum Brain Mapp 18:1-12

Baudena P, Halgren E, Heit G, Clarke JM (1995) Intracerebral potentials to rare target and distractor auditory and visual stimuli. III. Frontal cortex. Electroencephalogr Clin Neurophysiol 94:251-264

Berlucchi G, Aglioti S (1997) The body in the brain: neural bases of corporeal awareness. Trends Neurosci 20:560-564

Blair RC, Karniski W (1993) An alternative method for significance testing of waveform difference potentials. Psychophysiology 30:518-524

Blakemore SJ, Frith C (2003) Self-awareness and action. Curr Opin Neurobiol 13:219-224
Boning J, Drechsler F, Neuhauser B (1989) Somatosensory eventrelated potentials and selective attention impairment in young chronic schizophrenics. Neuropsychobiology 21:146-151

Braff DL (1999) Psychophysiological and Information-processing Approached to Schizophrenia. In: Charney DS, Nestler EJ, Bunney BS (eds) Neurobiology of mental illness. Oxford University Press, New York, Oxford, pp 258-271

Bramon E, Rabe-Hesketh S, Sham P, Murray RM, Frangou S (2004) Meta-analysis of the P300 and P50 waveforms in schizophrenia. Schizophr Res 70:315-329

Brockhaus-Dumke A, Mueller R, Faigle U, Klosterkoetter J (2008) Sensory gating revisited: relation between brain oscillations and auditory evoked potentials in schizophrenia. Schizophr Res 99:238-249

Burton H (1986) Second somatosensory cortex and related areas. In: Jones EG, Peters A (eds) Cerebral cortex. Sensory-motor areas and aspects of cortical connectivity. Plenum Press, New York, pp 31-98

Carlson M (1981) Characteristics of sensory deficits following lesions of Brodmann's areas 1 and 2 in the postcentral gyrus of Macaca mulatta. Brain Res 204:424-430

Carter CS, Mintun M, Nichols T, Cohen JD (1997) Anterior cingulate gyrus dysfunction and selective attention deficits in schizophrenia: $[15 \mathrm{O}] \mathrm{H}_{2} \mathrm{O}$ PET study during single-trial Stroop task performance. Am J Psychiatry 154:1670-1675

Caselli RJ (1993) Ventrolateral and dorsomedial somatosensory association cortex damage produces distinct somesthetic syndromes in humans. Neurology 43:762-771

Catalan MJ, Honda M, Weeks RA, Cohen LG, Hallett M (1998) The functional neuroanatomy of simple and complex sequential finger movements: a PET study. Brain 121(Pt 2):253-264

Catts SV, Shelley AM, Ward PB, Liebert B, McConaghy N, Andrews S, Michie PT (1995) Brain potential evidence for an auditory sensory memory deficit in schizophrenia. Am J Psychiatry 152:213-219

Chang BP, Lenzenweger MF (2001) Somatosensory processing in the biological relatives of schizophrenia patients: a signal detection analysis of two-point discrimination. J Abnorm Psychol 110:433-442

Chang BP, Lenzenweger MF (2004) Investigating graphesthesia task performance in the biological relatives of schizophrenia patients. Schizophr Bull 30:327-334

Chang BP, Lenzenweger MF (2005) Somatosensory processing and schizophrenia liability: proprioception, exteroceptive sensitivity, and graphesthesia performance in the biological relatives of schizophrenia patients. J Abnorm Psychol 114:85-95

Chau W, McIntosh AR, Robinson SE, Schulz M, Pantev C (2004) Improving permutation test power for group analysis of spatially filtered MEG data. Neuroimage 23:983-996

Cheour M, Imada T, Taulu S, Ahonen A, Salonen J, Kuhl P (2004) Magnetoencephalography is feasible for infant assessment of auditory discrimination. Exp Neurol 190(Suppl 1):S44-S51

Clark VP, Fannon S, Lai S, Benson R, Bauer L (2000) Responses to rare visual target and distractor stimuli using event-related fMRI. J Neurophysiol 83:3133-3139

Clementz BA, Blumenfeld LD (2001) Multichannel electroencephalographic assessment of auditory evoked response suppression in schizophrenia. Exp Brain Res 139:377-390

Cohen JD, Forman SD, Braver TS, Casey BJ, Servan-Schreiber D, Noll DC (1994) Activation of prefrontal cortex in a non- spatial working memory task with functional MRI. 1st edn, pp 293-304

Cohen D, Schläpfer U, Ahlfors S, Hämäläinen M, Halgren E (2002) New six-layer magnetically-shielded room for MEG. In: Nowak HHJ, Gießler F (eds) Proceedings of the 13th international conference on biomagnetism. VDE Verlag, Jena, Germany, pp 919-921 
Corbetta M (1998) Frontoparietal cortical networks for directing attention and the eye to visual locations: identical, independent, or overlapping neural systems? Proc Natl Acad Sci USA 95: $831-838$

Cuffin BN, Schomer DL, Ives JR, Blume H (2001) Experimental tests of EEG source localization accuracy in realistically shaped head models. Clin Neurophysiol 112:2288-2292

Dale AM, Fischl B, Sereno MI (1999) Cortical surface-based analysis. I. Segmentation and surface reconstruction. Neuroimage 9: 179-194

Dale AM, Liu AK, Fischl BR, Buckner RL, Belliveau JW, Lewine JD, Halgren E (2000) Dynamic statistical parametric mapping: combining fMRI and MEG for high-resolution imaging of cortical activity. Neuron 26:55-67

Danckert J, Saoud M, Maruff P (2004) Attention, motor control and motor imagery in schizophrenia: implications for the role of the parietal cortex. Schizophr Res 70:241-261

Dassonville P, Lewis SM, Zhu XH, Ugurbil K, Kim SG, Ashe J (1998) Effects of movement predictability on cortical motor activation. Neurosci Res 32:65-74

Davidoff RA (1990) The pyramidal tract. Neurology 40:332-339

Desmedt JE, Tomberg C (1989) Mapping early somatosensory evoked potentials in selective attention: critical evaluation of control conditions used for titrating by difference the cognitive P30, P40, P100 and N140. Electroencephalogr Clin Neurophysiol 74:321-346

Dworkin RH (1994) Pain insensitivity in schizophrenia: a neglected phenomenon and some implications. Schizophr Bull 20:235-248

Edgar JC, Miller GA, Moses SN, Thoma RJ, Huang MX, Hanlon FM, Weisend MP, Sherwood A, Bustillo J, Adler LE, Canive JM (2005) Cross-modal generality of the gating deficit. Psychophysiology 42:318-327

Edgar JC, Hanlon FM, Huang MX, Weisend MP, Thoma RJ, Carpenter B, Hoechstetter K, Canive JM, Miller GA (2008) Superior temporal gyrus spectral abnormalities in schizophrenia. Psychophysiology 45:812-824

Ferguson AS, Zhang X, Stroink G (1994) A complete linear discretization for calculating the magnetic field using the boundary element method. IEEE Trans Biomed Eng 41:455-460

Fernandes LO, Keller J, Giese-Davis JE, Hicks BD, Klein DN, Miller GA (1999) Converging evidence for a cognitive anomaly in early psychopathology. Psychophysiology 36:511-521

Fischl B, van der KA, Destrieux C, Halgren E, Segonne F, Salat DH, Busa E, Seidman LJ, Goldstein J, Kennedy D, Caviness V, Makris N, Rosen B, Dale AM (2004) Automatically parcellating the human cerebral cortex. Cereb Cortex 14:11-22

Ford JM, Pfefferbaum A, Roth W (1992) P3 and schizophrenia. Ann NY Acad Sci 658:146-162

Forss N, Jousmaki V (1998) Sensorimotor integration in human primary and secondary somatosensory cortices. Brain Res 781:259-267

Forss N, Hari R, Salmelin R, Ahonen A, Hamalainen M, Kajola M, Knuutila J, Simola J (1994) Activation of the human posterior parietal cortex by median nerve stimulation. Exp Brain Res 99:309-315

Friedman DP (1991) Endogenous scalp-recorded brain potentials in schizophrenia: a methodological review. In: Steinhauer SR, Gruzelier JH, Zubin J (eds) Endogenous scalp-recorded brain potentials in schizophrenia: a methodological review. Elsevier, Amsterdam, pp 91-127

Friedman DP, Murray EA, O’Neill JB, Mishkin M (1986) Cortical connections of the somatosensory fields of the lateral sulcus of macaques: evidence for a corticolimbic pathway for touch. J Comp Neurol 252:323-347

Fujiwara N, Imai M, Nagamine T, Mima T, Oga T, Takeshita K, Toma K, Shibasaki H (2002) Second somatosensory area (SII) plays a significant role in selective somatosensory attention. Brain Res Cogn Brain Res 14:389-397

Galan L, Biscay R, Rodriguez JL, Perez-Abalo MC, Rodriguez R (1997) Testing topographic differences between event related brain potentials by using non-parametric combinations of permutation tests. Electroencephalogr Clin Neurophysiol 102: 240-247

Garcia-Larrea L, Lukaszewicz AC, Mauguiere F (1995) Somatosensory responses during selective spatial attention: the N120-toN140 transition. Psychophysiology 32:526-537

Gazzaley A, D'Esposito M (2008) Top-down mudulation in visual working memory. Working memory: behavioral and neural correlates, pp 197-211

Gencer NG, Tanzer IO (1999) Forward problem solution of electromagnetic source imaging using a new BEM formulation with high-order elements. Phys Med Biol 44:2275-2287

Giese-Davis JE, Miller GA, Knight RA (1993) Memory template comparison processes in anhedonia and dysthymia. Psychophysiology 30:646-656

Goodale MA, Milner AD (1992) Separate visual pathways for perception and action. Trends Neurosci 15:20-25

Gordon AM, Lee JH, Flament D, Ugurbil K, Ebner TJ (1998) Functional magnetic resonance imaging of motor, sensory, and posterior parietal cortical areas during performance of sequential typing movements. Exp Brain Res 121:153-166

Green MF, Kern RS, Heaton RK (2004) Longitudinal studies of cognition and functional outcome in schizophrenia: implications for MATRICS. Schizophr Res 72:41-51

Gudlowski Y, Ozgurdal S, Witthaus H, Gallinat J, Hauser M, Winter C, Uhl I, Heinz A, Juckel G (2009) Serotonergic dysfunction in the prodromal, first-episode and chronic course of schizophrenia as assessed by the loudness dependence of auditory evoked activity. Schizophr Res 109:141-147

Halgren E, Squires NK, Wilson CL, Rohrbaugh JW, Babb TL, Crandall PH (1980) Endogenous potentials generated in the human hippocampal formation and amygdala by infrequent events. Science 210:803-805

Halgren E, Baudena P, Clarke JM, Heit G, Liegeois C, Chauvel P, Musolino A (1995a) Intracerebral potentials to rare target and distractor auditory and visual stimuli. I. Superior temporal plane and parietal lobe. Electroencephalogr Clin Neurophysiol 94: $191-220$

Halgren E, Baudena P, Clarke JM, Heit G, Marinkovic K, Devaux B, Vignal JP, Biraben A (1995b) Intracerebral potentials to rare target and distractor auditory and visual stimuli. II. Medial, lateral and posterior temporal lobe. Electroencephalogr Clin Neurophysiol 94:229-250

Halgren E, Marinkovic K, Chauvel P (1998) Generators of the late cognitive potentials in auditory and visual oddball tasks. Electroencephalogr Clin Neurophysiol 106:156-164

Hamalainen MS, Sarvas J (1989) Realistic conductivity geometry model of the human head for interpretation of neuromagnetic data. IEEE Trans Biomed Eng 36:165-171

Hanlon FM, Weisend MP, Huang M, Lee RR, Moses SN, Paulson KM, Thoma RJ, Miller GA, Canive JM (2003) A non-invasive method for observing hippocampal function. Neuroreport 14:1957-1960

Hari R, Forss N (1999) Magnetoencephalography in the study of human somatosensory cortical processing. Philos Trans R Soc Lond B Biol Sci 354:1145-1154

Hari R, Hamalainen H, Hamalainen M, Kekoni J, Sams M, Tiihonen J (1990) Separate finger representations at the human second somatosensory cortex. Neuroscience 37:245-249

Hari R, Karhu J, Hamalainen M, Knuutila J, Salonen O, Sams M, Vilkman V (1993) Functional organization of the human first and second somatosensory cortices: a neuromagnetic study. Eur J Neurosci 5:724-734 
Harrington DL, Rao SM, Haaland KY, Bobholz JA, Mayer AR, Binderx JR, Cox RW (2000) Specialized neural systems underlying representations of sequential movements. J Cogn Neurosci 12:56-77

He B, Lian J, Spencer KM, Dien J, Donchin E (2001) A cortical potential imaging analysis of the P300 and novelty P3 components. Hum Brain Mapp 12:120-130

Hegerl U, Frodl-Bauch T (1997) Dipole source analysis of P300 component of the auditory evoked potential: a methodological advance? Psychiatry Res 74:109-118

Higashima M, Urata K, Kawasaki Y, Maeda Y, Sakai N, Mizukoshi C, Nagasawa T, Kamiya T, Yamaguchi N, Koshino Y (1998) P300 and the thought disorder factor extracted by factor-analytic procedures in schizophrenia. Biol Psychiatry 44:115-120

Huang MX, Aine C, Davis L, Butman J, Christner R, Weisend M, Stephen J, Meyer J, Silveri J, Herman M, Lee RR (2000) Sources on the anterior and posterior banks of the central sulcus identified from magnetic somatosensory evoked responses using multistart spatio-temporal localization. Hum Brain Mapp 11: $59-76$

Huang M, Davis LE, Aine C, Weisend M, Harrington D, Christner R, Stephen J, Edgar JC, Herman M, Meyer J, Paulson K, Martin K, Lee RR (2004a) MEG response to median nerve stimulation correlates with recovery of sensory and motor function after stroke. Clin Neurophysiol 115:820-833

Huang MX, Shih JJ, Lee RR, Harrington DL, Thoma RJ, Weisend MP, Hanlon F, Paulson KM, Li T, Martin K, Millers GA, Canive JM (2004b) Commonalities and differences among vectorized beamformers in electromagnetic source imaging. Brain Topogr 16:139-158

Huang MX, Lee RR, Miller GA, Thoma RJ, Hanlon FM, Paulson KM, Martin K, Harrington DL, Weisend MP, Edgar JC, Canive JM (2005) A parietal-frontal network studied by somatosensory oddball MEG responses, and its cross-modal consistency. Neuroimage 28:99-114

Huang MX, Dale AM, Song T, Halgren E, Harrington DL, Podgorny I, Canive JM, Lewis S, Lee RR (2006) Vector-based spatialtemporal minimum L1-norm solution for MEG. Neuroimage 31:1025-1037

Ikebuchi E, Nakagome K, Tugawa R, Asada Y, Mori K, Takahashi N, Takazawa S, Ichikawa I, Akaho R (1996) What influences social skills in patients with schizophrenia? Preliminary study using the role play test, WAIS-R and event-related potential. Schizophr Res 22:143-150

Javitt DC, Doneshka P, Zylberman I, Ritter W, Vaughan HG Jr (1993) Impairment of early cortical processing in schizophrenia: an event-related potential confirmation study. Biol Psychiatry 33:513-519

Javitt DC, Doneshka P, Grochowski S, Ritter W (1995) Impaired mismatch negativity generation reflects widespread dysfunction of working memory in schizophrenia. Arch Gen Psychiatry 52:550-558

Jeon YW, Polich J (2001) P300 asymmetry in schizophrenia: a metaanalysis. Psychiatry Res 104:61-74

Jeon YW, Polich J (2003) Meta-analysis of P300 and schizophrenia: patients, paradigms, and practical implications. Psychophysiology 40:684-701

Johannesen JK, Kieffaber PD, O'Donnell BF, Shekhar A, Evans JD, Hetrick WP (2005) Contributions of subtype and spectral frequency analyses to the study of P50 ERP amplitude and suppression in schizophrenia. Schizophr Res 78:269-284

Johnstone EC, Crow TJ, Johnson AL, MacMillan JF (1986) The Northwick Park Study of first episodes of schizophrenia. I. Presentation of the illness and problems relating to admission. $\mathrm{Br}$ J Psychiatry 148:115-120
Johnstone EC, Leary J, Frith CD, Owens DG (1991) Disabilities and circumstances of schizophrenic patients-a follow-up study. Police contact. Br J Psychiatry Suppl 13:37-39, 44-46

Jones EG, Coulter JD, Hendry SH (1978) Intracortical connectivity of architectonic fields in the somatic sensory, motor and parietal cortex of monkeys. J Comp Neurol 181:291-347

Jones EG, Coulter JD, Wise SP (1979) Commissural columns in the sensory-motor cortex of monkeys. J Comp Neurol 188: $113-$

135

Jousmaki V, Forss N (1998) Effects of stimulus intensity on signals from human somatosensory cortices. Neuroreport 9:3427-3431

Juckel G, Gallinat J, Riedel M, Sokullu S, Schulz C, Moller HJ, Muller N, Hegerl U (2003) Serotonergic dysfunction in schizophrenia assessed by the loudness dependence measure of primary auditory cortex evoked activity. Schizophr Res 64:115-124

Juckel G, Mavrogiorgou P, Bredemeier S, Gallinat J, Frodl T, Schulz C, Moller HJ, Hegerl U (2004) Loudness dependence of primary auditory-cortex-evoked activity as predictor of therapeutic outcome to prophylactic lithium treatment in affective disorders-a retrospective study. Pharmacopsychiatry 37:46-51

Juckel G, Gudlowski Y, Muller D, Ozgurdal S, Brune M, Gallinat J, Frodl T, Witthaus H, Uhl I, Wutzler A, Pogarell O, Mulert C, Hegerl U, Meisenzahl EM (2008) Loudness dependence of the auditory evoked N1/P2 component as an indicator of serotonergic dysfunction in patients with schizophrenia-a replication study. Psychiatry Res 158:79-82

Kaiser J, Lutzenberger W (2005) Human gamma-band activity: a window to cognitive processing. Neuroreport 16:207-211

Kaiser J, Lutzenberger W, Preissl H, Mosshammer D, Birbaumer N (2000) Statistical probability mapping reveals high-frequency magnetoencephalographic activity in supplementary motor area during self-paced finger movements. Neurosci Lett 283:81-84

Kaiser J, Ripper B, Birbaumer N, Lutzenberger W (2003) Dynamics of gamma-band activity in human magnetoencephalogram during auditory pattern working memory. Neuroimage 20:816-827

Kaiser J, Hertrich I, Ackermann H, Lutzenberger W (2006) Gammaband activity over early sensory areas predicts detection of changes in audiovisual speech stimuli. Neuroimage 30:13761382

Kandel ER, Schwartz JH, Jessell TM (2000) Principles of neural science, 4th edn. McGraw-Hill, New York

Karniski W, Blair RC, Snider AD (1994) An exact statistical method for comparing topographic maps, with any number of subjects and electrodes. Brain Topogr 6:203-210

Kasai K, Okazawa K, Nakagome K, Hiramatsu K, Hata A, Fukuda M, Honda M, Miyauchi M, Matsushita M (1999) Mismatch negativity and $\mathrm{N} 2 \mathrm{~b}$ attenuation as an indicator for dysfunction of the preattentive and controlled processing for deviance detection in schizophrenia: a topographic event-related potential study. Schizophr Res 35:141-156

Kawamura T, Nakasato N, Seki K, Kanno A, Fujita S, Fujiwara S, Yoshimoto T (1996) Neuromagnetic evidence of pre- and postcentral cortical sources of somatosensory evoked responses. Electroencephalogr Clin Neurophysiol 100:44-50

Kekoni J, Hamalainen H, McCloud V, Reinikainen K, Naatanen R (1996) Is the somatosensory N250 related to deviance discrimination or conscious target detection? Electroencephalogr Clin Neurophysiol 100:115-125

Kettner RE, Marcario JK, Clark-Phelps MC (1996) Control of remembered reaching sequences in monkey. I. Activity during movement in motor and premotor cortex. Exp Brain Res 112:335-346

Kiehl KA, Liddle PF (2001) An event-related functional magnetic resonance imaging study of an auditory oddball task in schizophrenia. Schizophr Res 48:159-171 
Kiss I, Dashieff RM, Lordeon P (1989) A parieto-occipital generator for P300: evidence from human intracranial recordings. Int $\mathrm{J}$ Neurosci 49:133-139

Knight RT, Scabini D, Woods DL, Clayworth CC (1989) Contributions of temporal-parietal junction to the human auditory P3. Brain Res 502:109-116

Kolb B, Whishaw IQ (1996) Fundamentals of human neuropsychology, 4th edn. W.H. Freeman, New York, NY

Kreitschmann-Andermahr I, Rosburg T, Meier T, Volz HP, Nowak H, Sauer H (1999) Impaired sensory processing in male patients with schizophrenia: a magnetoencephalographic study of auditory mismatch detection. Schizophr Res 35:121-129

Kreitschmann-Andermahr I, Rosburg T, Demme U, Gaser E, Nowak $H$, Sauer H (2001) Effect of ketamine on the neuromagnetic mismatch field in healthy humans. Brain Res Cogn Brain Res 12:109-116

Kurata K (1991) Corticocortical inputs to the dorsal and ventral aspects of the premotor cortex of macaque monkeys. Neurosci Res 12:263-280

Kurata K, Hoffman DS (1994) Differential effects of muscimol microinjection into dorsal and ventral aspects of the premotor cortex of monkeys. J Neurophysiol 71:1151-1164

Lang AH, Eerola O, Korpilahti P, Holopainen I, Salo S, Aaltonen O (1995) Practical issues in the clinical application of mismatch negativity. Ear Hear 16:118-130

Lemon RN (1981) Variety of functional organization within the monkey motor cortex. J Physiol 311:521-540

Lemon RN, Porter R (1976) Afferent input to movement-related precentral neurones in conscious monkeys. Proc R Soc Lond B Biol Sci 194:313-339

Lemon RN, van der Burg J (1979) Short-latency peripheral inputs to thalamic neurones projecting to the motor cortex in the monkey. Exp Brain Res 36:445-462

Lenzenweger MF (2000) Two-point discrimination thresholds and schizotypy: illuminating a somatosensory dysfunction. Schizophr Res 42:111-124

Lenzenweger MF, Nakayama K, Chang BP (2002) Methodological excursions in pursuit of a somatosensory dysfunction in schizotypy and schizophrenia. In: Maher BA, Lenzenweger MF, Hooley JM (eds) Principles of experimental psychopathology: essays in honor of Brendan A. Maher (decade of behavior). American Psychological Association, USA

Light GA, Braff DL (2005) Mismatch negativity deficits are associated with poor functioning in schizophrenia patients. Arch Gen Psychiatry 62:127-136

Linden DE, Prvulovic D, Formisano E, Vollinger M, Zanella FE, Goebel R, Dierks T (1999) The functional neuroanatomy of target detection: an fMRI study of visual and auditory oddball tasks. Cereb Cortex 9:815-823

Lovrich D, Novick B, Vaughan HG Jr (1988) Topographic analysis of auditory event-related potentials associated with acoustic and semantic processing. Electroencephalogr Clin Neurophysiol 71:40-54

Lutzenberger W, Ripper B, Busse L, Birbaumer N, Kaiser J (2002) Dynamics of gamma-band activity during an audiospatial working memory task in humans. J Neurosci 22:5630-5638

Maris E (2004) Randomization tests for ERP topographies and whole spatiotemporal data matrices. Psychophysiology 41:142-151

Maris E, Oostenveld R (2007) Nonparametric statistical testing of EEG- and MEG-data. J Neurosci Methods 164:177-190

Maris E, Schoffelen JM, Fries P (2007) Nonparametric statistical testing of coherence differences. J Neurosci Methods 163:161175

Martin P, Tewesmeier M, Albers M, Schmid GB, Scharfetter C (1995) Towards an understanding of sensory soft signs of schizophrenia. Psychopathology 28:281-284
Mathalon DH, Ford JM, Pfefferbaum A (2000) Trait and state aspects of P300 amplitude reduction in schizophrenia: a retrospective longitudinal study. Biol Psychiatry 47:434-449

Matsuoka H, Saito H, Ueno T, Sato M (1996) Altered endogenous negativities of the visual event-related potential in remitted schizophrenia. Electroencephalogr Clin Neurophysiol 100: $18-24$

Mauguiere F, Merlet I, Forss N, Vanni S, Jousmaki V, Adeleine P, Hari R (1997a) Activation of a distributed somatosensory cortical network in the human brain. A dipole modelling study of magnetic fields evoked by median nerve stimulation. Part I: location and activation timing of SEF sources. Electroencephalogr Clin Neurophysiol 104:281-289

Mauguiere F, Merlet I, Forss N, Vanni S, Jousmaki V, Adeleine P, Hari R (1997b) Activation of a distributed somatosensory cortical network in the human brain: a dipole modelling study of magnetic fields evoked by median nerve stimulation. Part II: effects of stimulus rate, attention and stimulus detection. Electroencephalogr Clin Neurophysiol 104:290-295

McCarthy G, Wood CC (1987) Intracranial recordings of endogenous ERPs in humans. Electroencephalogr Clin Neurophysiol Suppl 39:331-337

McCarthy G, Blamire AM, Puce A, Nobre AC, Bloch G, Hyder F, Goldman-Rakic P, Shulman RG (1994) Functional magnetic resonance imaging of human prefrontal cortex activation during a spatial working memory task. Proc Natl Acad Sci USA 91:8690-8694

McCarthy G, Puce A, Constable RT, Krystal JH, Gore JC, GoldmanRakic P (1996) Activation of human prefrontal cortex during spatial and nonspatial working memory tasks measured by functional MRI. Cereb Cortex 6:600-611

McCarthy G, Luby M, Gore J, Goldman-Rakic P (1997) Infrequent events transiently activate human prefrontal and parietal cortex as measured by functional MRI. J Neurophysiol 77:1630-1634

Menon V, Ford JM, Lim KO, Glover GH, Pfefferbaum A (1997) Combined event-related fMRI and EEG evidence for temporalparietal cortex activation during target detection. Neuroreport 8:3029-3037

Miller GA, Elbert T, Sutton BP, Heller W (2007) Innovative clinical assessment technologies: challenges and opportunities in neuroimaging. Psychol Assess 19:58-73

Mima T, Nagamine T, Nakamura K, Shibasaki H (1998) Attention modulates both primary and second somatosensory cortical activities in humans: a magnetoencephalographic study. J Neurophysiol 80:2215-2221

Mishkin M (1979) Analogous neural models for tactual and visual learning. Neuropsychologia 17:139-151

Mosher JC, Leahy RM, Lewis PS (1999) EEG and MEG: forward solutions for inverse methods. IEEE Trans Biomed Eng 46: 245-259

Mushiake H, Inase M, Tanji J (1991) Neuronal activity in the primate premotor, supplementary, and precentral motor cortex during visually guided and internally determined sequential movements. J Neurophysiol 66:705-718

Naatanen R (1995) The mismatch negativity: a powerful tool for cognitive neuroscience. Ear Hear 16:6-18

Naatanen R (2001) The perception of speech sounds by the human brain as reflected by the mismatch negativity (MMN) and its magnetic equivalent (MMNm). Psychophysiology 38:1-21

Naatanen R (2003) Mismatch negativity: clinical research and possible applications. Int J Psychophysiol 48:179-188

Naatanen R, Alho K (1995) Mismatch negativity-a unique measure of sensory processing in audition. Int $\mathrm{J}$ Neurosci 80:317-337

Naatanen R, Alho K (1997) Mismatch negativity - the measure for central sound representation accuracy. Audiol Neurootol 2: $341-353$ 
Naatanen R, Paavilainen P, Alho K, Reinikainen K, Sams M (1987) The mismatch negativity to intensity changes in an auditory stimulus sequence. Electroencephalogr Clin Neurophysiol Suppl 40:125-131

Neshige R, Luders H (1992) Recording of event-related potentials (P300) from human cortex. J Clin Neurophysiol 9:294-298

Nichols TE, Holmes AP (2002) Nonparametric permutation tests for functional neuroimaging: a primer with examples. Hum Brain Mapp 15:1-25

Norra C, Waberski TD, Kawohl W, Kunert HJ, Hock D, Gobbele R, Buchner H, Hoff P (2004) High-frequency somatosensory thalamocortical oscillations and psychopathology in schizophrenia. Neuropsychobiology 49:71-80

Nyffeler T, Gutbrod K, Pflugshaupt T, von WR, Hess CW, Muri RM (2005) Allocentric and egocentric spatial impairments in a case of topographical disorientation. Cortex 41:133-143

O’Donnell BF, Cohen RA, Hokama H, Cuffin BN, Lippa C, Shenton ME, Drachman DA (1993) Electrical source analysis of auditory ERPs in medial temporal lobe amnestic syndrome. Electroencephalogr Clin Neurophysiol 87:394-402

Oades RD, ttmann-Balcar A, Zerbin D, Grzella I (1997) Impaired attention-dependent augmentation of MMN in nonparanoid vs paranoid schizophrenic patients: a comparison with obsessivecompulsive disorder and healthy subjects. Biol Psychiatry 41:1196-1210

Pantazis D, Nichols TE, Baillet S, Leahy RM (2005) A comparison of random field theory and permutation methods for the statistical analysis of MEG data. Neuroimage 25:383-394

Park HJ, Kwon JS, Youn T, Pae JS, Kim JJ, Kim MS, Ha KS (2002) Statistical parametric mapping of LORETA using high density EEG and individual MRI: application to mismatch negativities in schizophrenia. Hum Brain Mapp 17:168-178

Pekkonen E, Katila H, Ahveninen J, Karhu J, Huotilainen M, Tiihonen J (2002) Impaired temporal lobe processing of preattentive auditory discrimination in schizophrenia. Schizophr Bull 28:467-474

Pfefferbaum A, Ford JM, White PM, Roth WT (1989) P3 in schizophrenia is affected by stimulus modality, response requirements, medication status, and negative symptoms. Arch Gen Psychiatry 46:1035-1044

Polich J, Kok A (1995) Cognitive and biological determinants of P300: an integrative review. Biol Psychol 41:103-146

Pritchard WS (1986) Cognitive event-related potential correlates of schizophrenia. Psychol Bull 100:43-66

Randolph M, Semmes J (1974) Behavioral consequences of selective subtotal ablations in the postcentral gyrus of Macaca mulatta. Brain Res 70:55-70

Rao SM, Binder JR, Bandettini PA, Hammeke TA, Yetkin FZ, Jesmanowicz A, Lisk LM, Morris GL, Mueller WM, Estkowski LD (1993) Functional magnetic resonance imaging of complex human movements. Neurology 43:2311-2318

Ridley RM, Ettlinger G (1978) Further evidence of impaired tactile learning after removals of the second somatic sensory projection cortex (SII) in the monkey. Exp Brain Res 31:475-488

Ritzler B, Rosenbaum G (1974) Proprioception in schizophrenics and normals: effects of stimulus intensity and interstimulus interval. J Abnorm Psychol 83:106-111

Rosen I, Asanuma H (1972) Peripheral afferent inputs to the forelimb area of the monkey motor cortex: input-output relations. Exp Brain Res 14:257-273

Sadato N, Campbell G, Ibanez V, Deiber M, Hallett M (1996) Complexity affects regional cerebral blood flow change during sequential finger movements. J Neurosci 16:2691-2700

Schlitt HA, Heller L, Aaron R, Best E, Ranken DM (1995) Evaluation of boundary element methods for the EEG forward problem: effect of linear interpolation. IEEE Trans Biomed Eng 42:52-58
Shagass C, Roemer RA, Straumanis JJ, Amadeo M (1978) Evoked potential correlates of psychosis. Biol Psychiatry 13:163-184

Shagass C, Roemer RA, Straumanis JJ, Josiassen RC (1985) Combinations of evoked potential amplitude measurements in relation to psychiatric diagnosis. Biol Psychiatry 20:701-722

Shean G, Faia C (1975) Autonomic control, selective attention and schizophrenic subtype. J Nerv Ment Dis 160:176-181

Shelley AM, Ward PB, Catts SV, Michie PT, Andrews S, McConaghy N (1991) Mismatch negativity: an index of a preattentive processing deficit in schizophrenia. Biol Psychiatry 30:1059-1062

Shibasaki H, Sadato N, Lyshkow H, Yonekura Y, Honda M, Nagamine T, Suwazono S, Magata Y, Ikeda A, Miyazaki M (1993) Both primary motor cortex and supplementary motor area play an important role in complex finger movement. Brain 116(Pt 6):1387-1398

Shinozaki N, Yabe H, Sato Y, Hiruma T, Sutoh T, Nashida T, Matsuoka T, Kaneko S (2002) The difference in Mismatch negativity between the acute and post-acute phase of schizophrenia. Biol Psychol 59:105-119

Simson R, Vaughan HG, Ritter W (1976) The scalp topography of potentials associated with missing visual or auditory stimuli. Electroencephalogr Clin Neurophysiol 40:33-42

Smith EE, Jonides J (1997) Working memory: a view from neuroimaging. Cognit Psychol 33:5-42

Smith ME, Halgren E, Sokolik M, Baudena P, Musolino A, LiegeoisChauvel C, Chauvel P (1990) The intracranial topography of the P3 event-related potential elicited during auditory oddball. Electroencephalogr Clin Neurophysiol 76:235-248

Snyder E, Hillyard SA, Galambos R (1980) Similarities and differences among the P3 waves to detected signals in three modalities. Psychophysiology 17:112-122

Solodkin A, Hlustik P, Noll DC, Small SL (2001) Lateralization of motor circuits and handedness during finger movements. Eur $\mathbf{J}$ Neurol 8:425-434

Spiegel J, Tintera J, Gawehn J, Stoeter P, Treede RD (1999) Functional MRI of human primary somatosensory and motor cortex during median nerve stimulation. Clin Neurophysiol 110:47-52

Stapleton JM, Halgren E (1987) Endogenous potentials evoked in simple cognitive tasks: depth components and task correlates. Electroencephalogr Clin Neurophysiol 67:44-52

Stevens AA, Skudlarski P, Gatenby JC, Gore JC (2000) Event-related fMRI of auditory and visual oddball tasks. Magn Reson Imaging 18:495-502

Tarkka IM, Stokic DS, Basile LF, Papanicolaou AC (1995) Electric source localization of the auditory P300 agrees with magnetic source localization. Electroencephalogr Clin Neurophysiol 96:538-545

Taulu S, Simola J (2006) Spatiotemporal signal space separation method for rejecting nearby interference in MEG measurements. Phys Med Biol 51:1759-1768

Taulu S, Kajola M, Simola J (2004a) Suppression of interference and artifacts by the Signal Space Separation Method. Brain Topogr $16: 269-275$

Taulu S, Simola J, Kajola M (2004) MEG recordings of DC fields using the signal space separation method (SSS). Neurol Clin Neurophysiol 2004:35

Thoma RJ, Hanlon FM, Huang M, Miller GA, Moses SN, Weisend MP, Jones A, Paulson KM, Irwin J, Canive JM (2007) Impaired secondary somatosensory gating in patients with schizophrenia. Psychiatry Res 151:189-199

Thonnessen H, Zvyagintsev M, Harke KC, Boers F, Dammers J, Norra C, Mathiak K (2008) Optimized mismatch negativity paradigm reflects deficits in schizophrenia patients A combined EEG and MEG study. Biol Psychol 77:205-216

Turetsky BI, Colbath EA, Gur RE (1998) P300 subcomponent abnormalities in schizophrenia: I. Physiological evidence for 
gender and subtype specific differences in regional pathology. Biol Psychiatry 43:84-96

Turetsky BI, Colbath EA, Gur RE (2004) P300 subcomponent abnormalities in schizophrenia: II. Longitudinal stability and relationship to symptom change. Biol Psychiatry 43:331-339

Turetsky BI, Greenwood TA, Olincy A, Radant AD, Braff DL, Cadenhead KS, Dobie DJ, Freedman R, Green MF, Gur RE, Gur RC, Light GA, Mintz J, Nuechterlein KH, Schork NJ, Seidman LJ, Siever LJ, Silverman JM, Stone WS, Swerdlow NR, Tsuang DW, Tsuang MT, Calkins ME (2008) Abnormal auditory N100 amplitude: a heritable endophenotype in first-degree relatives of schizophrenia probands. Biol Psychiatry 64:1051-1059

Umbricht D, Javitt D, Novak G, Bates J, Pollack S, Lieberman J, Kane J (1998) Effects of clozapine on auditory event-related potentials in schizophrenia. Biol Psychiatry 44:716-725

Valkonen-Korhonen M, Purhonen M, Tarkka IM, Sipila P, Partanen J, Karhu J, Lehtonen J (2003) Altered auditory processing in acutely psychotic never-medicated first-episode patients. Brain Res Cogn Brain Res 17:747-758

Waberski TD, Gobbele R, Darvas F, Schmitz S, Buchner H (2002) Spatiotemporal imaging of electrical activity related to attention to somatosensory stimulation. Neuroimage 17:1347-1357
Wang J, Hiramatsu K, Hokama H, Miyazato H, Ogura C (2003) Abnormalities of auditory P300 cortical current density in patients with schizophrenia using high density recording. Int $\mathrm{J}$ Psychophysiol 47:243-253

Wexler BE, Fulbright RK, Lacadie CM, Skudlarski P, Kelz MB, Constable RT, Gore JC (1997) An fMRI study of the human cortical motor system response to increasing functional demands. Magn Reson Imaging 15:385-396

Wojciulik E, Kanwisher N, Driver J (1998) Covert visual attention modulates face-specific activity in the human fusiform gyrus: fMRI study. J Neurophysiol 79:1574-1578

Yamaguchi S, Knight RT (1991) P300 generation by novel somatosensory stimuli. Electroencephalogr Clin Neurophysiol 78:50-55

Yingling CD, Hosobuchi Y (1984) A subcortical correlate of P300 in man. Electroencephalogr Clin Neurophysiol 59:72-76

Yoshiura T, Zhong J, Shibata DK, Kwok WE, Shrier DA, Numaguchi Y (1999) Functional MRI study of auditory and visual oddball tasks. Neuroreport 10:1683-1688 